\title{
Results of the 2007 B100 Quality Survey
}

Technical Report NREL/TP-540-42787

March 2008

T. L. Alleman and R. L. McCormick

NREL is operated by Midwest Research Institute • Battelle

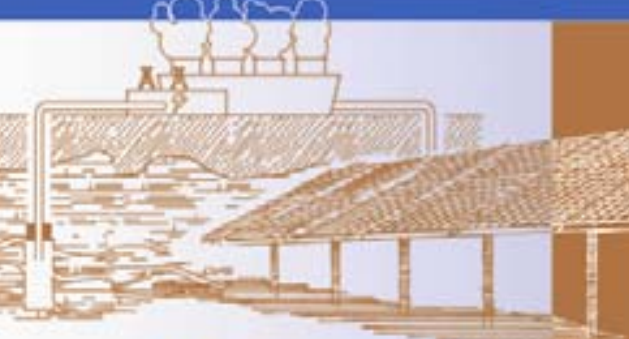

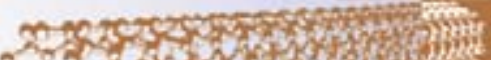
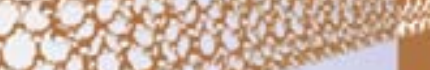

Contract No. DE-AC36-99-G010337

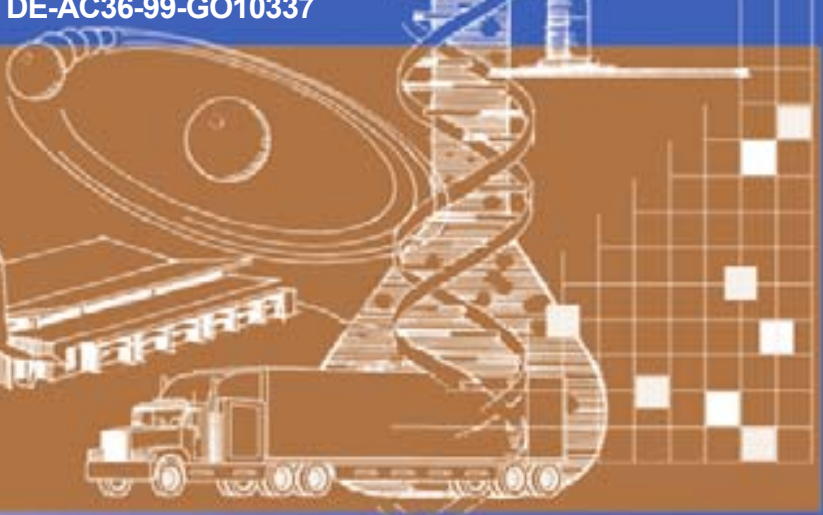




\section{Results of the 2007 B100 Quality Survey}

\section{Technical Report NREL/TP-540-42787 \\ March 2008}

T. L. Alleman and R. L. McCormick

Prepared under Task No. FC08.9400

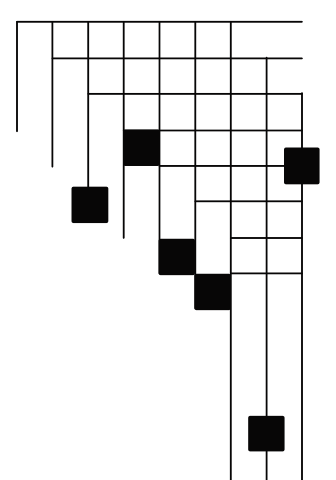

National Renewable Energy Laboratory

1617 Cole Boulevard, Golden, Colorado 80401-3393

303-275-3000 • www.nrel.gov

Operated for the U.S. Department of Energy

Office of Energy Efficiency and Renewable Energy

by Midwest Research Institute • Battelle

Contract No. DE-AC36-99-G010337 


\section{NOTICE}

This report was prepared as an account of work sponsored by an agency of the United States government. Neither the United States government nor any agency thereof, nor any of their employees, makes any warranty, express or implied, or assumes any legal liability or responsibility for the accuracy, completeness, or usefulness of any information, apparatus, product, or process disclosed, or represents that its use would not infringe privately owned rights. Reference herein to any specific commercial product, process, or service by trade name, trademark, manufacturer, or otherwise does not necessarily constitute or imply its endorsement, recommendation, or favoring by the United States government or any agency thereof. The views and opinions of authors expressed herein do not necessarily state or reflect those of the United States government or any agency thereof.

Available electronically at http://www.osti.gov/bridge

Available for a processing fee to U.S. Department of Energy and its contractors, in paper, from:

U.S. Department of Energy

Office of Scientific and Technical Information

P.O. Box 62

Oak Ridge, TN 37831-0062

phone: 865.576 .8401

fax: 865.576 .5728

email: mailto:reports@adonis.osti.gov

Available for sale to the public, in paper, from:

U.S. Department of Commerce

National Technical Information Service

5285 Port Royal Road

Springfield, VA 22161

phone: 800.553.6847

fax: 703.605.6900

email: orders@ntis.fedworld.gov

online ordering: http://www.ntis.gov/ordering.htm 


\section{Acknowledgments}

The authors would like to thank Scott Fenwick of Archer Daniels Midland for the methanol analysis of the samples. This report was prepared by staff of the U.S. Department of Energy's National Renewable Energy Laboratory. 


\section{Executive Summary}

To evaluate the quality of biodiesel (B100) fuel being produced in the United States, research staff members at the U.S. Department of Energy's National Renewable Energy Laboratory conduct periodic B100 quality surveys. In order to be a legal fuel and qualify for tax credits, B100 must meet ASTM International D6751 specifications.

For the 2007 survey, samples were collected directly from U.S. producers between April and November 2007. The samples were compared against the National Biodiesel Accreditation Program (BQ-9000) critical properties (except sulfur) and metals using ASTM International test methods. These properties are a subset of the full ASTM D6751 B100 requirements.

Samples were requested from all 107 producers, as determined from the National Biodiesel Board at the start of the survey. The 56 producers that provided samples represented $52 \%$ of the producers in the marketplace. Of the other 51 producers, 38 did not have product available, 7 did not respond, four declined to participate, one had shut down its plant to perform upgrades, and one no longer existed.

The samples were tested for properties deemed critical for engine operation: oxidation stability, flash point and alcohol content, cloud point, water and sediment, acid value, and free and total glycerin. They were also analyzed for the following elements: phosphorus, sodium, potassium, magnesium, and calcium. These elements are potent poisons for advanced emission control equipment.

The samples collected represented $70 \%$ of the U.S. market in 2007, or 278 million gallons. The BQ- 9000 producers accounted for $74 \%$ of the volume in the survey. Based on the samples, $89.6 \%$ of the biodiesel was on specification. Large producers and BQ-9000 producers hardly ever failed to meet the specifications. Small and medium producers had significant failure rates; however, combined, they account for only approximately $11 \%$ of the market by volume.

Small and medium biodiesel producers failed to meet the oxidation stability specification most often, and $30 \%$ of their samples failed. Failure rates for all other properties were less than $10 \%$. Eight producers out of the 56 respondents failed to meet specifications for multiple properties.

Seventeen samples in the survey were collected from BQ-9000 producers, which included 14 large producers and three medium ones. These samples were overwhelmingly on specification, with the exception of one. This sample failed to meet the D2709 water and sediment specification, indicating that contamination of the sample was likely.

Although failure rates were high on a percentage-of-samples-collected basis, a volume weighting indicated that only $10 \%$ of the biodiesel in the United States failed to meet these properties. The BQ-9000 companies, regardless of production volume, had extremely low failure rates in comparison to those of the overall sample population of biodiesel producers. 


\section{Table of Contents}

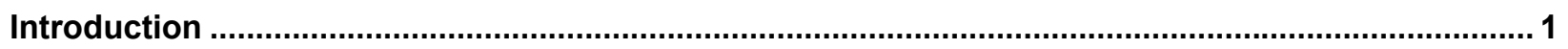

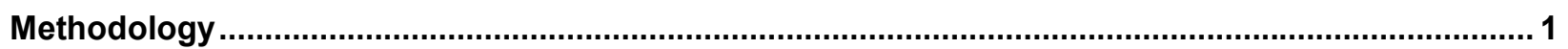

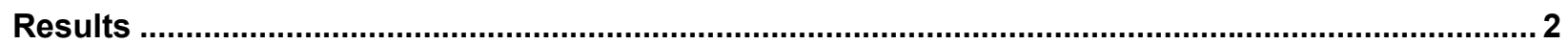

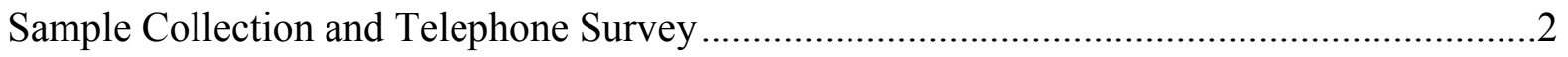

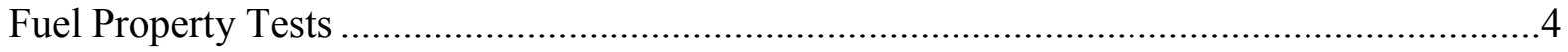

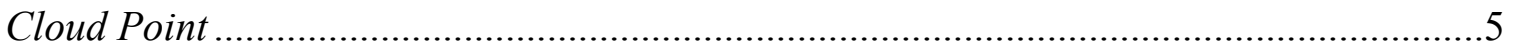

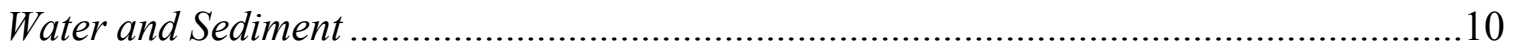

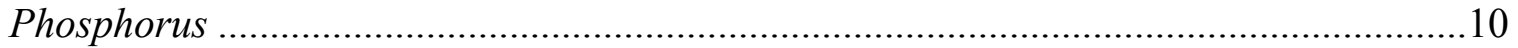

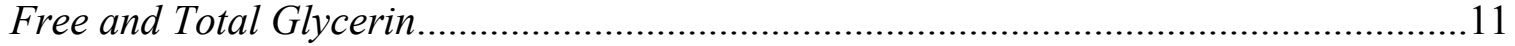

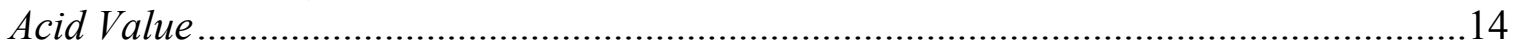

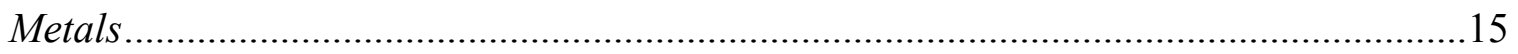

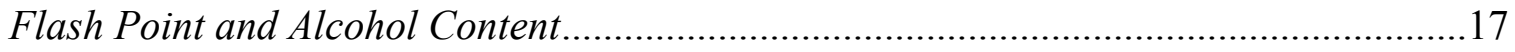

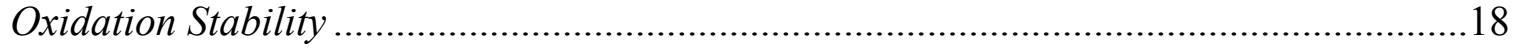

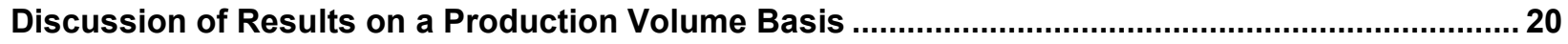

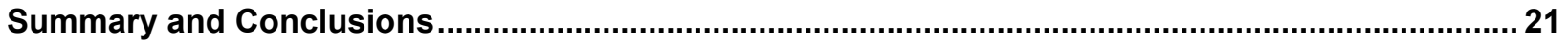




\section{List of Figures}

Figure 1. Biodiesel production and number of producers by size category................................

Figure 2. Cloud point for 2007 B100 quality survey samples .................................................

Figure 3. Relative unsaturation vs. cloud point of B100 samples ..........................................

Figure 4. Phosphorus content of B100 samples.................................................................10

Figure 5. Free glycerin content of B100 samples .................................................................

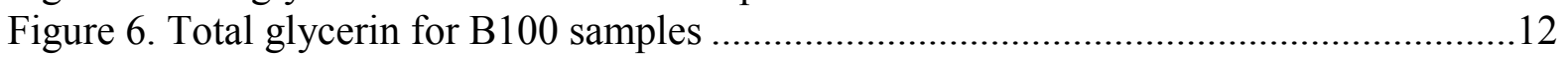

Figure 7. Mono-, di-, and triglyceride content of biodiesel samples ......................................13

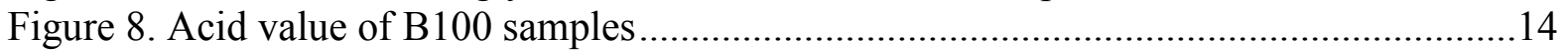

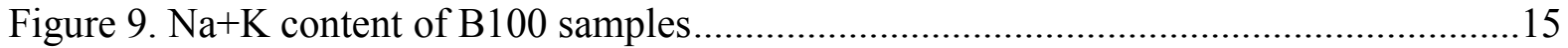

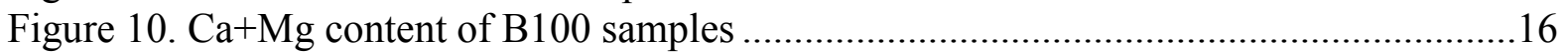

Figure 11. Flash point results for B100 quality survey........................................................17

Figure 12. Oxidation stability results for B100 samples.....................................................19

Figure 13. Oxidation stability histogram for biodiesel samples ...........................................20

\section{List of Tables}

Table 1. Properties and Specification Limits for 2007 B100 Quality Survey ............................2

Table 2. Responses to Sample Collection Efforts..................................................................2

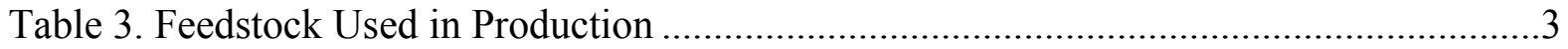

Table 4. Techniques to Ensure Homogeneity of Product and/or Product Tanks........................

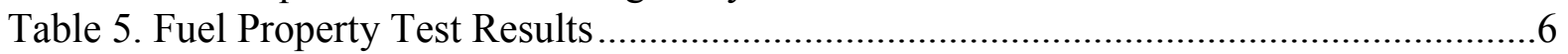




\section{Abbreviations}

$\begin{array}{ll}\text { B100 } & \text { neat biodiesel } \\ \text { BQ-9000 } & \text { National Biodiesel Accreditation Program requirements } \\ \text { degrees Celsius } \\ { }^{\circ} \mathrm{A} & \text { American Society for Testing and Materials } \\ \mathrm{Ca} & \text { calcium } \\ \mathrm{EN} & \text { European Normalization } \\ \mathrm{FAME} & \text { fatty acid methyl ester } \\ \mathrm{h} & \text { hour, hours } \\ \mathrm{K} & \text { potassium } \\ \mathrm{M} & \text { million } \\ \mathrm{mass} \% & \text { percent by mass } \\ \mathrm{max} & \text { maximum } \\ \mathrm{Mg} & \text { magnesium } \\ \mathrm{mgKOH} / \mathrm{g} & \text { milligrams potassium hydroxide per gram of sample } \\ \mathrm{min} & \text { minimum } \\ \mathrm{Na} & \text { sodium } \\ \mathrm{NREL} & \text { National Renewable Energy Laboratory } \\ \mathrm{P} & \text { phosphorus } \\ \mathrm{ppb} & \text { parts per billion } \\ \mathrm{ppm} & \text { parts per million } \\ \mathrm{vol} \% & \text { percent by volume }\end{array}$




\section{Introduction}

The biodiesel market has experienced rapid growth in the past few years. The volume of biodiesel produced in the United States has nearly doubled each year since 2004. Much of this growth can be attributed to the enactment of a tax credit to encourage biodiesel production. In order to be a legal fuel and allow producers and blenders to claim the tax credit, biodiesel (B100) must meet ASTM International (ASTM) D6751 specifications.

As part of an effort to help the biodiesel industry obtain warranty approval from engine manufacturers for the use of biodiesel blends, the U.S. Department of Energy's National Renewable Energy Laboratory (NREL) has conducted nationwide surveys of biodiesel quality. NREL conducted a B100 quality survey in 2004, and the survey results showed that approximately $85 \%$ of the samples met the quality standards of ASTM D6751-03a, the version of D6751 that was in effect at the time. ${ }^{1}$ In 2006, NREL published the results of a B100 quality survey that used samples collected at terminals. The results of that study showed that $59 \%$ of the biodiesel samples collected failed to meet D6751. ${ }^{2}$ To determine the volume weighted quality of the B100 market, NREL conducted a B100 survey in summer 2007, collecting B100 samples from numerous producers. This report details the results of that survey.

\section{Methodology}

Biodiesel samples were collected from producers in the United States beginning in April 2007 and concluding in November 2007. One hundred seven producers were contacted for this survey. Each producer was contacted by a subcontractor and asked to provide a sample of biodiesel for the survey.

In addition to the request for a B100 sample, each producer was asked a list of questions regarding its production facility. These questions included the production volume; anticipated expansion volume, if applicable; whether the producer was compliant with the requirements of the National Biodiesel Accreditation Program (BQ-9000) or planned to become so; the type of feedstock; how the B100 was stored; and the markets into which its product was sold.

The B100 sample test matrix was determined by the Biodiesel Blend Evaluation Team, an industry steering group composed mainly of engine manufacturers. The test matrix included properties deemed most critical to engine operability and emission control system durability. These properties were oxidation stability, flash point and alcohol content, cloud point, water and sediment, acid value, free and total glycerin, phosphorus, sodium, potassium, calcium, and magnesium. The samples were also tested for cold soak filtration and FAME components, which will be the subject of a future report. Table 1 lists the properties tested in this study.

\footnotetext{
${ }^{1}$ McCormick, R.L.; Alleman, T.L.; Ratcliff, M.; Moens, L.; Lawrence, R. Survey of the Quality and Stability of Biodiesel and Biodiesel Blends in the United States in 2004. NREL Technical Report TP-540-38836, October 2004.

${ }^{2}$ Alleman, T.L; McCormick, R.L.; Deutch, S. 2006 B100 Quality Survey Results: Milestone Report. NREL Technical Report TP-540-41549, May 2007.
} 
The test methods and applicable specification limits are also listed. All testing was conducted using ASTM or EN test methods with no deviations or modifications.

Table 1. Properties and Specification Limits for 2007 B100 Quality Survey

\begin{tabular}{|c|c|c|}
\hline Property & Test Method $^{\mathrm{a}}$ & Specification Limits in D6751 \\
\hline Cloud point, ${ }^{\circ} \mathrm{C}$ & $\mathrm{D} 2500$ & Report \\
\hline Water and sediment, vol\% & D2709 & $0.05 \max$ \\
\hline Phosphorus, ppm & D4951 & $10 \max$ \\
\hline Free glycerin, mass $\%$ & D6584 & $0.020 \max$ \\
\hline Total glycerin, mass $\%$ & D6584 & $0.240 \max$ \\
\hline Acid value, $\mathrm{mgKOH} / \mathrm{g}$ & D664 & $0.50 \max$ \\
\hline Calcium+magnesium, combined, ppm & D7111 & $5 \max$ \\
\hline Sodium+potassium, combined, ppm & D7111 & $5 \max$ \\
\hline Flash point, ${ }^{\circ} \mathrm{C}$ & D93 & $\begin{array}{c}130 \text { max } \\
\text { or } \\
93 \text { min }+ \text { methanol content } \\
0.20 \text { mass } \% \text { max }\end{array}$ \\
\hline Methanol content, ${ }^{\mathrm{b}}$ mass $\%$ & EN14110 & $0.20 \max$ \\
\hline Oxidation stability, $\mathrm{h}$ & EN14112 & $3 \min$ \\
\hline
\end{tabular}

(a) ASTM test method unless otherwise noted.

(b) Tested only if applicable.

\section{Results}

\section{Sample Collection and Telephone Survey}

Each producer contacted for a sample was assigned a numerical identifier between 1 and 107; these are used consistently throughout this report. Values with no data indicate that the producer did not participate in the survey for the reasons discussed below.

Of the 107 producers listed at the start of this study, 52\% provided samples for the survey (56 producers). The response to sample collection efforts is summarized in Table 2. Each producer was contacted a maximum of four times in an effort to obtain a sample. One plant was shut down for upgrades, and one no longer existed. The other 49 producers provided a variety of reasons for not participating. The most common response to a sample request was that no product was available.

Table 2. Responses to Sample Collection Efforts

\begin{tabular}{|l|c|}
\hline Response & Number Responding \\
\hline Affirmative & 56 \\
\hline No response & 7 \\
\hline No product available & 38 \\
\hline Not interested in participating & 4 \\
\hline Plant upgrade & 1 \\
\hline No longer exists & 1 \\
\hline
\end{tabular}

The total U.S. biodiesel production volume in 2007 was approximately 394 million gallons. This survey covered producers of $70 \%$ of this volume, or 287 million gallons. Because actual production volumes are considered proprietary, the National Biodiesel Board was asked to bin the participating producers by production size. Producers were binned into small, medium, and large categories. Small producers reported volumes of less than 100,000 gallons in 2007. 
Medium producers reported between 100,000 and 1 million gallons, and large producers reported production volumes of more than 1 million gallons. On average, large producers make over 16 million gallons per year. Figure 1 shows the distribution of the participating producers by production volume. The respondents to the survey were fairly evenly split between small, medium, and large producers ( 25 small, 16 medium, and 15 large).

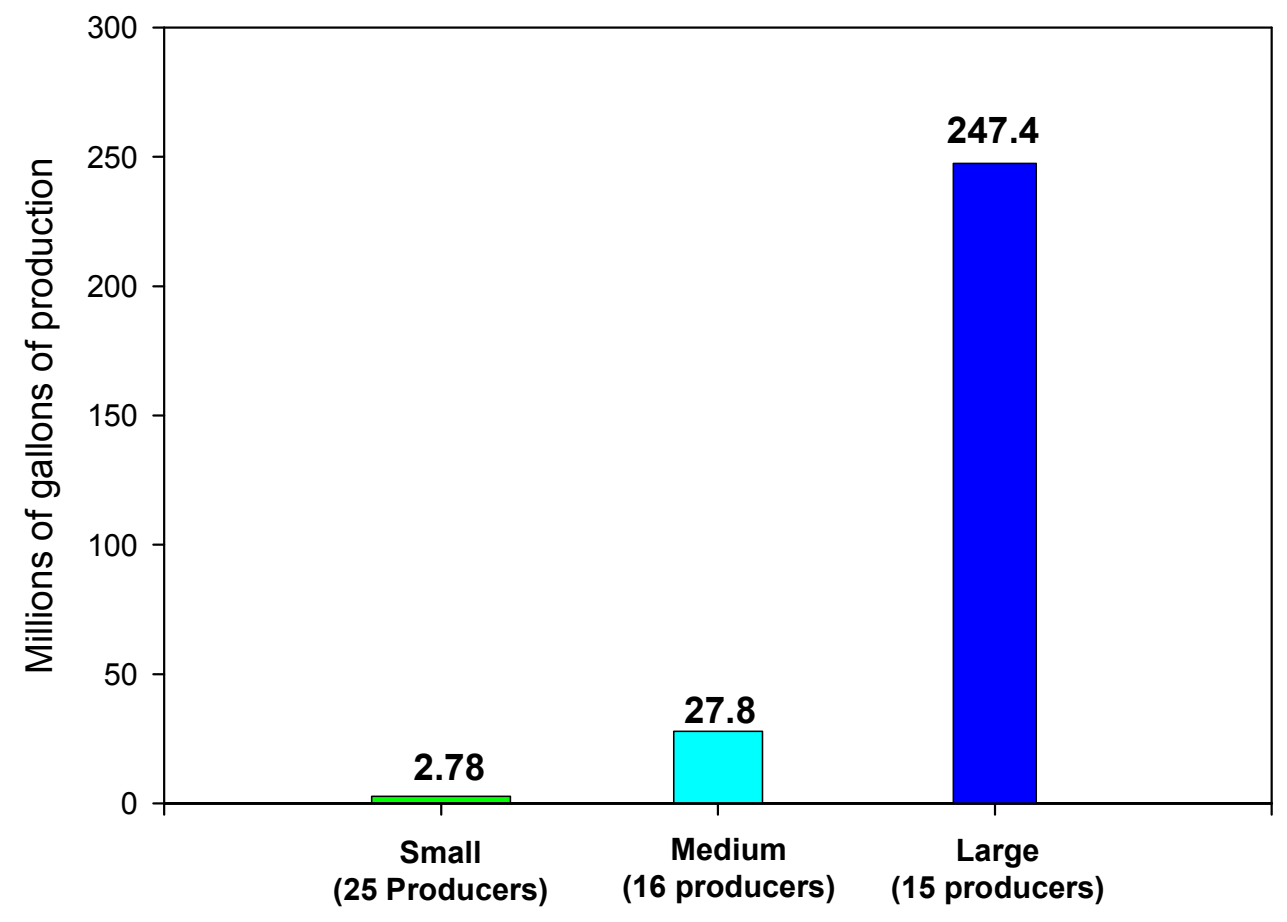

Figure 1. Biodiesel production and number of producers by size category

Each producer was asked to identify the feedstock used in biodiesel production. Table 3 shows the types of feedstocks identified and the frequency for each feedstock. This survey shows the wide variety of feedstocks used in the United States. The National Biodiesel Board estimates that approximately $90 \%$ of the biodiesel in the United States is produced from soy, indicating that most of the large producers are using soy.

Table 3. Feedstock Used in Production

\begin{tabular}{|l|c|c|}
\hline Response & Frequency & $\begin{array}{c}\text { Production Volume, } \\
\text { million gallons }\end{array}$ \\
\hline Soybean oil & 17 & 96.7 \\
\hline No response or not specified & 15 & 146.8 \\
\hline Used oil & 11 & 2.8 \\
\hline Animal fat & 6 & 5.5 \\
\hline Mixed vegetable/animal & 3 & 18.3 \\
\hline Cottonseed & 2 & 0.22 \\
\hline Mixed vegetable oils & 1 & 16.5 \\
\hline Canola & 1 & 0.11 \\
\hline
\end{tabular}


At the time of the survey, there were 19 BQ-9000 producers. Two of the BQ-9000 producers did not participate in the survey; one might not have participated because of a shutdown for plant upgrades. Nine additional producers indicated they were under review to become BQ9000 producers, and nine others indicated interest in the program. The remaining 21

producers either made no statement about BQ-9000 or had no plans to participate in the BQ9000 program at this time.

Participants were asked how they ensured the homogeneity of their product and/or product tanks. The responses are outlined in Table 4 below. Not including the nonresponses, a vast majority of biodiesel production is accomplished using mixing/recirculation or continuousflow processes to ensure the homogeneity of the product and/or product tanks, along with quality testing.

Table 4. Techniques to Ensure Homogeneity of Product and/or Product Tanks

\begin{tabular}{|l|c|}
\hline Response & Frequency \\
\hline Mixing or recirculation & 15 \\
\hline N/A or no response & 14 \\
\hline Continuous flow & 7 \\
\hline Density or specific gravity & 7 \\
\hline Testing & 7 \\
\hline Nothing & 2 \\
\hline Same as BQ-9000 & 3 \\
\hline Fill from bottom and draw from top & 1 \\
\hline
\end{tabular}

\section{Fuel Property Tests}

Results from the fuel property tests are shown in Table 5. Results are listed in numerical order. For a case in which no sample was received, the data field has been omitted. Results in boldface type indicate a failure to meet the specification in place at the time of this study.

Large producers and BQ-9000 producers (several of whom are medium-size producers) almost always met the property specifications. Small and medium producers not participating in the BQ-9000 program experienced more difficulty in meeting the specification limits. Samples from the 25 small producers met the specifications $28 \%$ of the time. Sixty-eight percent of the medium producers failed to meet specifications. Eight producers failed to meet multiple property tests.

The highest failure rate was for oxidation stability; $30 \%$ of the samples did not meet the 3hour specification. Notably, oxidation stability is the newest requirement in D6751, taking effect in January 2007. Those samples represented approximately 8.5 million gallons of the total 287 million gallons covered in the survey. All other tests had a failure rate of $10 \%$ or less.

Seventeen BQ-9000 producers participated in the survey. One sample from one producer was off specification for water and sediment, and this was likely the result of contamination. In the 2004 and 2006 NREL biodiesel quality surveys, no samples failed the water and sediment specification. 


\section{Cloud Point}

The cloud point, while having no specification limit in D6751, is an important parameter for the cold weather operability of fuels. The cloud point of the fuels varied from $-5^{\circ} \mathrm{C}$ to $15^{\circ} \mathrm{C}$; the average was $2.4^{\circ} \mathrm{C}$ and the mode and median value, $0^{\circ} \mathrm{C}$. Figure 2 shows the cloud point results for the samples collected. The feedstock symbol is based on information provided by the producer during the telephone survey. Some discrepancies exist between the cloud point of the fuel and the reported feedstock. For example, the measured cloud point of sample \#6, reported to be soy-derived, was $12^{\circ} \mathrm{C}$. The technical literature indicates that soy-derived biodiesel has a cloud point ranging from $-2^{\circ} \mathrm{C}$ to $2^{\circ} \mathrm{C}{ }^{3}$ Thus, sample $\# 6$ is biodiesel derived from something other than pure soybean oil.

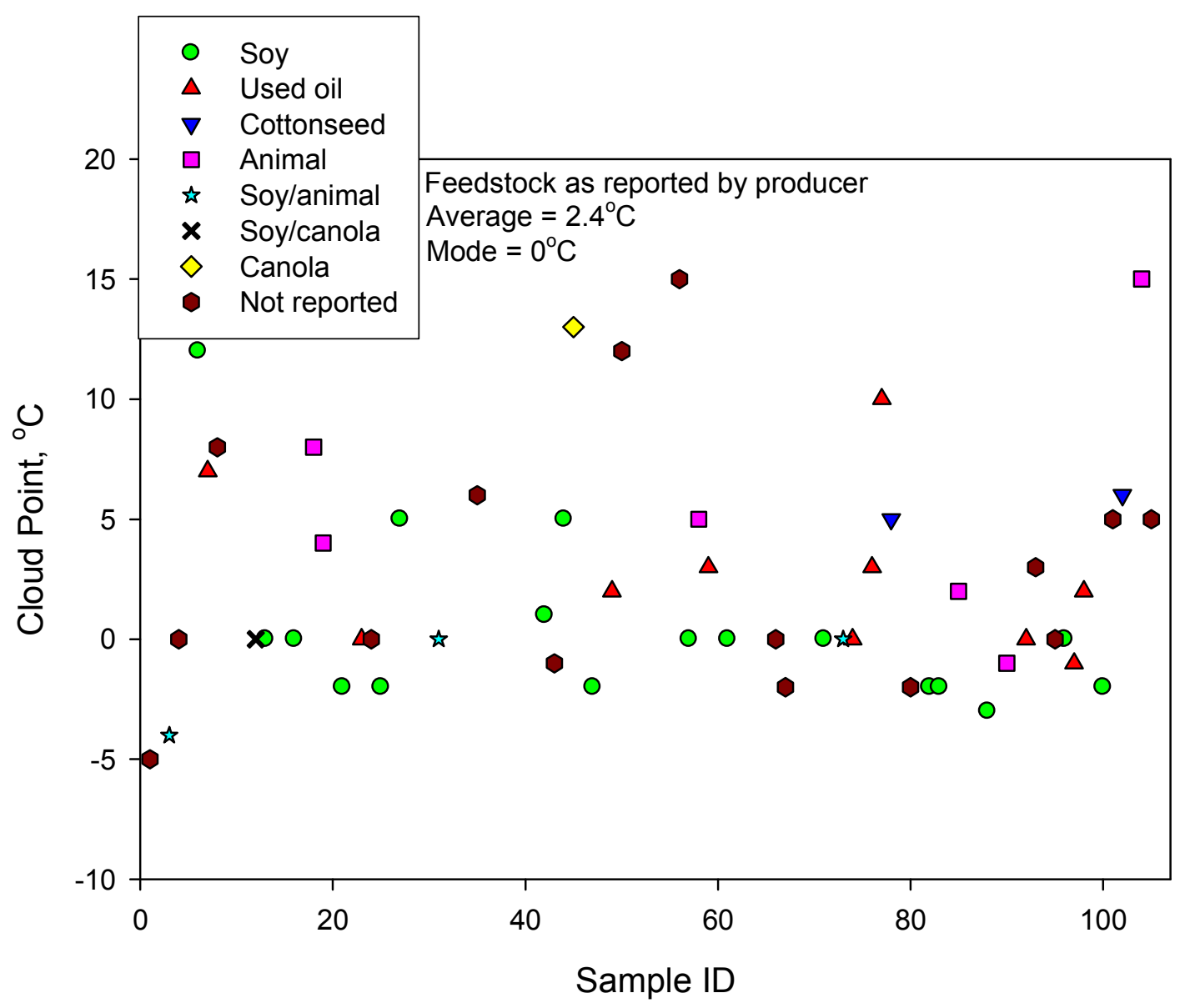

Figure 2. Cloud point for 2007 B100 quality survey samples

\footnotetext{
${ }^{3}$ Graboski, M.S.; McCormick, R.L. "Combustion of Fat and Vegetable Oil Derived Fuels in Diesel Engines." Progress in Energy and Combustion Science, 24, 125-163 (1998).
} 
Table 5. Fuel Property Test Results

\begin{tabular}{|c|c|c|c|c|c|c|c|c|c|c|c|c|c|c|c|}
\hline 亘 & 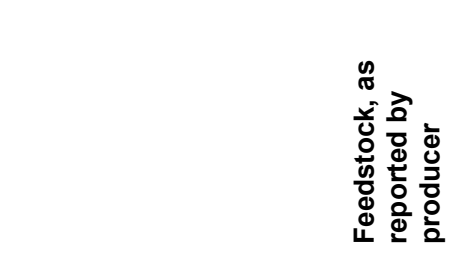 & 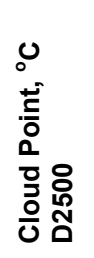 & 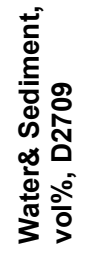 & 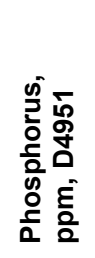 & 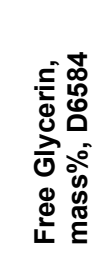 & 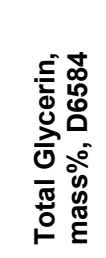 & 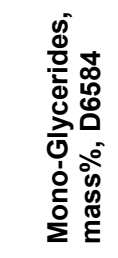 & 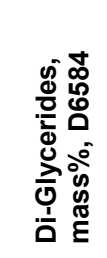 & 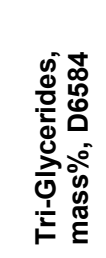 & 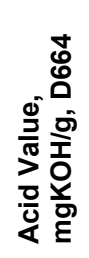 & 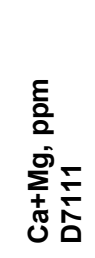 & 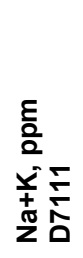 & $\begin{array}{l}0 \\
0 \\
\stackrel{ \pm}{0} \\
\overline{0} \\
\frac{0}{5} \\
\frac{0}{0} \\
\frac{\pi}{4}\end{array}$ & 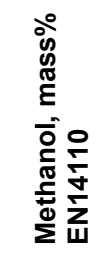 & 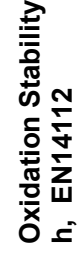 \\
\hline 1 & Not reported & -5 & 0.01 & $<5$ & ND & 0.077 & 0.257 & 0.062 & 0.017 & 0.14 & 0.20 & 2 & 167.8 & & 9.6 \\
\hline 3 & $\begin{array}{l}\text { Refined Soybean Oil and/or } \\
\text { Rendered Animal Fat }\end{array}$ & -4 & 0.01 & $<5$ & ND & 0.153 & 0.459 & 0.177 & 0.073 & 0.44 & 0.20 & 2 & 176.1 & & 3.2 \\
\hline 4 & Not reported & 0 & 0.01 & $<5$ & 0.005 & 0.140 & 0.474 & 0.078 & ND & 0.07 & 1.709 & 19.3 & 151.1 & & 0.3 \\
\hline 6 & Soybean oil & 12 & 0.01 & $<5$ & 0.005 & 0.122 & 0.402 & 0.071 & 0.026 & 0.18 & 0.20 & 2 & 140.6 & & 6.2 \\
\hline 7 & Used cooking oil & 7 & 0.01 & $<5$ & 0.006 & 0.210 & 0.55 & 0.194 & 0.315 & 0.27 & 0.20 & 2 & 166.1 & & 5.9 \\
\hline 8 & Fats & 8 & 0.01 & $<5$ & ND & 0.157 & 0.416 & 0.158 & 0.228 & 0.64 & 0.20 & 2 & 172.8 & & 3.7 \\
\hline 12 & $80 \%$ RBD soy $/ 20 \%$ crude canola & 0 & 0.01 & $<5$ & 0.012 & 0.174 & 0.535 & 0.158 & ND & 0.13 & 0.22 & 2 & 148.3 & & 3.2 \\
\hline 13 & Soy oil & 0 & 0.01 & $<5$ & ND & 0.067 & 0.605 & 0.056 & ND & 0.18 & 0.20 & 2 & 127.8 & 0.09 & 5.4 \\
\hline 16 & Soybean oil feedstock & 0 & 0.01 & $<5$ & 0.009 & 0.188 & 0.660 & 0.053 & ND & 0.19 & 0.20 & 2 & 152.2 & & 5.5 \\
\hline 18 & Choice white grease & 8 & 0.01 & $<5$ & ND & 0.030 & 0.114 & 0 & ND & 0.22 & 0.20 & 2 & 170.0 & & \\
\hline 19 & Poultry fat & 4 & 0.01 & $<5$ & 0.012 & 0.134 & 0.439 & 0.055 & ND & 0.14 & 0.462 & 2 & 117.8 & 0.20 & 4.7 \\
\hline 21 & Soy oil & -2 & 0.01 & $<5$ & ND & 0.137 & 0.489 & 0.071 & ND & 0.23 & 0.20 & 2 & 150.0 & & 7.0 \\
\hline 23 & Yellow grease & 0 & 0.01 & $<5$ & ND & 0.202 & 0.395 & 0.210 & 0.658 & 0.17 & 0.354 & 2 & 171.1 & & 4.0 \\
\hline 24 & Not reported & 0 & 0.01 & $<5$ & 0.005 & 0.167 & 0.563 & 0.092 & 0.022 & 0.17 & 0.20 & 2 & 110.0 & 0.006 & 6.2 \\
\hline 25 & Refined soy oil & -2 & 0.01 & $<5$ & ND & 0.167 & 0.611 & 0.063 & ND & 0.18 & 0.20 & 2 & 121.7 & 0.10 & 4.6 \\
\hline 27 & Soybean oil & 5 & 0.01 & $<5$ & ND & 0.234 & 0.753 & 0.222 & 0.051 & 0.46 & 0.248 & 2 & 193.9 & & 5.4 \\
\hline 31 & Soybean oil/poultry fat & 0 & 0.01 & $<5$ & ND & 0.146 & 0.510 & 0.077 & 0.025 & 0.18 & 0.20 & 2 & 180.0 & & 6.4 \\
\hline 35 & Not reported & 6 & 0.10 & $<5$ & 0.008 & 0.091 & 0.288 & 0.055 & ND & 0.20 & 0.20 & 2 & 177.2 & & 11.4 \\
\hline 42 & Soy oil & 1 & 0.01 & $<5$ & 0.007 & 0.174 & 0.585 & 0.093 & ND & 0.11 & 0.258 & 2 & 149.4 & & 7.4 \\
\hline 43 & Not reported & -1 & 0.01 & $<5$ & ND & 0.126 & 0.414 & 0.112 & 0.017 & 0.07 & 0.20 & 2 & 178.9 & & 7.2 \\
\hline 44 & Crude degummed soybean oil & 5 & 0.01 & $<5$ & ND & 0.200 & 0.654 & 0.180 & 0.033 & 0.14 & 0.598 & 6 & 133.9 & & 2.5 \\
\hline
\end{tabular}


Table 5. Fuel Property Test Results (continued)

\begin{tabular}{|c|c|c|c|c|c|c|c|c|c|c|c|c|c|c|c|}
\hline 苔 & 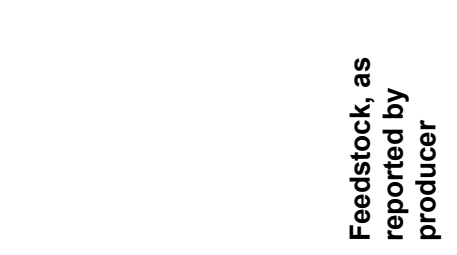 & 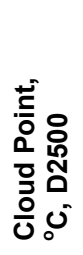 & 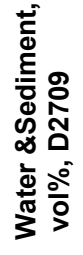 & 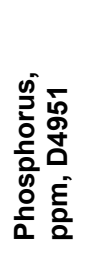 & 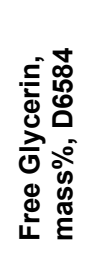 & 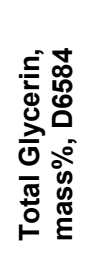 & 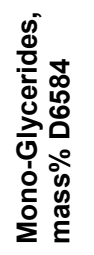 & 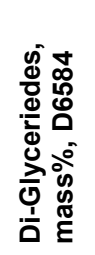 & 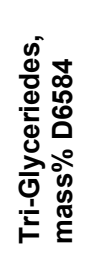 & 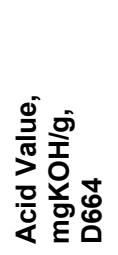 & 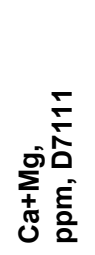 & 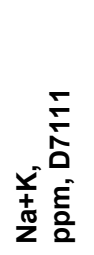 & 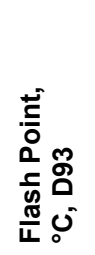 & 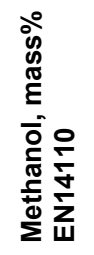 & 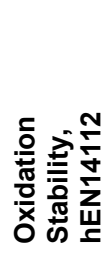 \\
\hline 45 & Canola & 13 & 0.01 & 21 & 0.075 & 1.150 & 0.554 & 1.065 & 7.404 & 0.2 & 0 & 0 & 27.0 & 2.00 & 6.0 \\
\hline 47 & Soybean oil & -2 & 0.01 & $<5$ & ND & 0.128 & 0.432 & 0.087 & 0.025 & 1.41 & 2.575 & 2 & 182.2 & & 0.8 \\
\hline 49 & WUO & 2 & 0.01 & $<5$ & 0.011 & 1.046 & 0.509 & 1.473 & 6.547 & 0.2 & 0.818 & 5 & 163.3 & & 0.3 \\
\hline 50 & Not reported & 12 & 0.01 & $<5$ & 0.007 & 0.073 & 0.192 & 0.091 & 0.026 & 0.19 & 0.20 & 3.6 & 155.6 & & 0.5 \\
\hline 56 & Not reported & 15 & 0.01 & $<5$ & ND & 0.114 & 0.367 & 0.104 & 0.031 & 0.16 & 0.534 & 2 & 165.0 & & 4.0 \\
\hline 57 & Refined soybean oil & 0 & 0.01 & $<5$ & 0.006 & 0.156 & 0.539 & 0.050 & 0.026 & 0.23 & 0.20 & 2 & 137.2 & & 6.5 \\
\hline 58 & Poultry & 5 & 0.01 & $<5$ & 0.007 & 0.060 & 0.157 & 0.071 & ND & 0.11 & 0.612 & 2 & 113.3 & 0.022 & 3.6 \\
\hline 59 & Used vegetable oil & 3 & 0.01 & $<5$ & ND & 0.177 & 0.612 & 0.122 & ND & 0.22 & 0.20 & 2 & 67.2 & & 1.1 \\
\hline 61 & Soy oil & 0 & 0.01 & $<5$ & ND & 0.164 & 0.585 & 0.064 & 0.027 & 0.42 & 0.20 & 2 & 132.8 & & 8.6 \\
\hline 66 & Not reported & 0 & 0.01 & $<5$ & 0.014 & ND & ND & ND & ND & 0.12 & 0.20 & 2 & 143.3 & & 8.2 \\
\hline 67 & Not reported & -2 & 0.01 & $<5$ & 0.005 & 0.126 & 0.438 & 0.042 & 0.019 & 0.40 & 0.419 & 2 & 172.2 & & 2.2 \\
\hline 69 & Used fryer oil (<7\% FFA) & & 0.01 & $<5$ & ND & 0.132 & 0.458 & 0.038 & 0.037 & 0.32 & 1.433 & 4.616 & 138.3 & & 1.8 \\
\hline 71 & Soybean oil & 0 & 0.01 & $<5$ & 0.006 & 0.170 & 0.522 & 0.195 & ND & 0.20 & 0.595 & 3 & 181.7 & & 4.8 \\
\hline 73 & Soy oil/virgin poultry fat & 0 & 0.01 & $<5$ & ND & 0.110 & 0.409 & 0.031 & ND & 0.37 & 0.20 & 2 & 105.6 & 0.028 & 4.5 \\
\hline 74 & Used vegetable oil & 0 & 0.01 & $<5$ & 0.036 & 0.305 & 0.532 & 0.253 & 0.894 & 0.16 & 1.871 & 83 & 105.6 & & 0.1 \\
\hline 76 & $100 \%$ used cooking oil & 3 & 0.01 & $<5$ & ND & 0.151 & 0.389 & 0.117 & 0.318 & 0.29 & 0.432 & 2 & 146.7 & & 0.9 \\
\hline 77 & $100 \%$ used cooking oil & 10 & 0.01 & $<5$ & ND & 0.112 & 0.394 & 0.053 & 0.02 & 0.24 & 0.504 & 2 & 176.7 & & 0.3 \\
\hline 78 & $100 \%$ cottonseed oil & 5 & 0.01 & $<5$ & ND & 0.073 & 0.223 & 0.070 & 0.021 & 0.12 & 8.119 & 2 & 173.3 & & 5.7 \\
\hline 80 & Not reported & -2 & 0.01 & $<5$ & ND & 0.280 & 0.942 & 0.206 & 0.028 & 1.64 & 0.413 & 2 & 163.3 & & 1.7 \\
\hline 82 & Virgin soybean oil (RB \& RBD) & -2 & 0.01 & $<5$ & 0.032 & 0.173 & 0.456 & 0.130 & 0.039 & 0.20 & 0.20 & 2 & 134.4 & & 4.5 \\
\hline 83 & Soybean oil & -2 & 0.01 & $<5$ & ND & 0.195 & 0.648 & 0.139 & 0.023 & 0.34 & 1.675 & 2.71 & 153.9 & & 2.9 \\
\hline 85 & Poultry fat & 2 & 0.01 & $<5$ & ND & 0.075 & 0.251 & 0.049 & 0.03 & 0.24 & 0.367 & 2 & 176.1 & & 4.9 \\
\hline
\end{tabular}


Table 5. Fuel Property Test Results (concluded)

\begin{tabular}{|c|c|c|c|c|c|c|c|c|c|c|c|c|c|c|c|}
\hline 亘 & 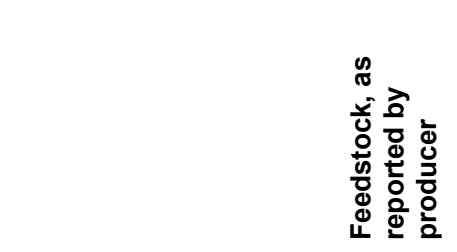 & 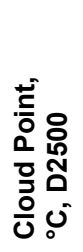 & 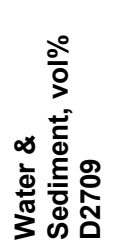 & 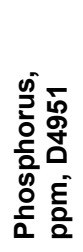 & 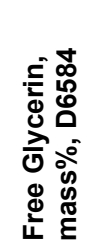 & 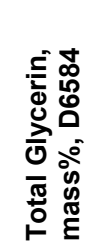 & 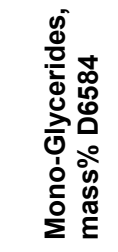 & 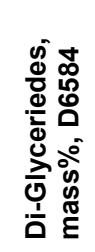 & 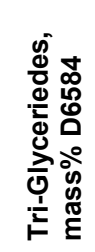 & 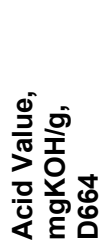 & 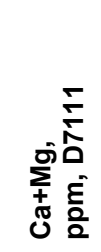 & 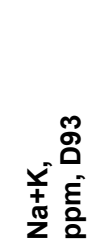 & 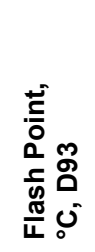 & 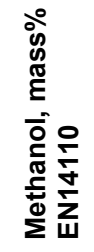 & 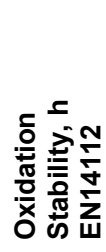 \\
\hline 90 & Choice white grease & -1 & 0.01 & $<5$ & ND & 0.147 & 0.478 & 0.113 & 0.066 & 0.27 & 29.1 & 4.9 & 166.1 & & 3.1 \\
\hline 92 & $\begin{array}{l}\text { Waste vegetable oil from } \\
\text { restaurants }\end{array}$ & 0 & 0.01 & $<5$ & ND & 0.197 & 0.546 & 0.179 & 0.274 & 0.36 & 0.977 & 2 & 175.0 & & 0.4 \\
\hline 93 & $\begin{array}{l}\text { Mixed oils (including yellow } \\
\text { grease) }\end{array}$ & 3 & 0.01 & $<5$ & ND & 0.094 & 0.288 & 0.107 & 0.036 & 0.08 & 0.435 & 2 & 167.2 & & 4.7 \\
\hline 95 & Not reported & 0 & 0.01 & $<5$ & 0.013 & 0.188 & 0.635 & 0.073 & ND & 0.38 & 0.297 & 2 & 133.0 & & 4.7 \\
\hline 96 & RBD soy oil & 0 & 0.01 & $<5$ & 0.007 & 0.655 & 1.398 & 1.736 & 0.261 & 0.32 & 1.214 & 5 & 108.3 & 0.21 & 0.2 \\
\hline 97 & Waste vegetable oil & -1 & 0.01 & $<5$ & ND & 0.143 & 0.450 & 0.159 & 0.021 & 0.21 & 0.292 & 2 & 164.4 & & 0.6 \\
\hline 98 & $100 \%$ used cooking oil & 2 & 0.01 & $<5$ & ND & 0.155 & 0.424 & 0.052 & 0.357 & 0.18 & 0.422 & 2.2 & 167.2 & & 2.4 \\
\hline 100 & Crude degummed soybean oil & -2 & 0.01 & $<5$ & ND & 0.129 & 0.430 & 0.087 & 0.024 & 0.18 & 2.137 & 2 & 156.1 & & 2.2 \\
\hline 101 & Not reported & 5 & 0.01 & $<5$ & ND & 0.152 & 0.483 & 0.124 & 0.039 & 0.18 & 0.279 & 2 & 167.8 & & 4.3 \\
\hline 102 & $100 \%$ cottonseed oil & 6 & 0.01 & $<5$ & ND & 0.060 & 0.209 & 0.045 & ND & 0.05 & 0.51 & 2 & 192.0 & & 5.5 \\
\hline 104 & Poultry fat & 15 & 0.01 & $<5$ & 0.011 & 0.130 & 0.425 & 0.063 & ND & 0.67 & 6.591 & 4.572 & 133.9 & & 3.2 \\
\hline 105 & Not reported & 5 & 0.01 & $<5$ & ND & 0.134 & 0.472 & 0.066 & 0.017 & 0.22 & 0.2 & 2 & 177.2 & & 8.0 \\
\hline
\end{tabular}


Another way to look at cloud point is by the relative degree of unsaturation of fatty acid methyl ester. Highly unsaturated feedstocks, like soy and cottonseed, will have lower cloud points than more saturated feedstocks, like palm and some animal fats. Figure 3 shows the cloud point in comparison to the relative unsaturation of the feedstock.

Highly unsaturated feedstocks will have the lowest cloud point, less than $5^{\circ} \mathrm{C}$. Moderately saturated biodiesels will have cloud points between $5^{\circ} \mathrm{C}$ and $10^{\circ} \mathrm{C}$. Highly saturated feedstocks will have cloud points greater than $10^{\circ} \mathrm{C}$. Figure 3 shows that a majority of samples received were predominantly unsaturated, with both a mean and mode cloud point of less than $5^{\circ} \mathrm{C}$.

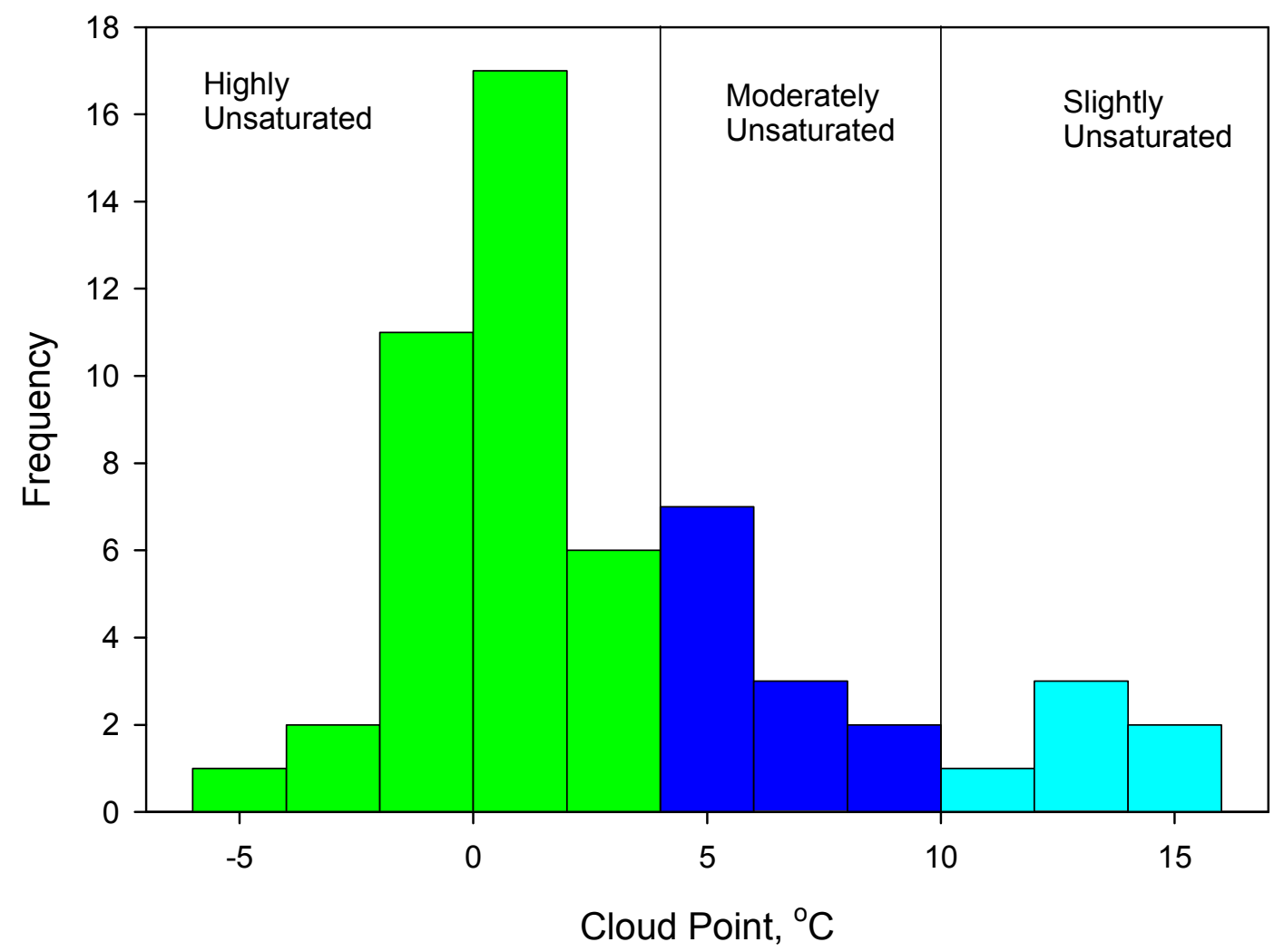

Figure 3. Relative unsaturation vs. cloud point of B100 samples 


\section{Water and Sediment}

Previous B100 surveys have discussed the importance of water and sediment in biodiesel. In this survey, only one sample failed to meet the water and sediment specification and was roughly twice the specification limit. Given the otherwise high quality of this sample, the high water and sediment is likely the result of contamination that occurred after production. Previous B100 quality surveys have shown every fuel meeting the current water and sediment specification.

\section{Phosphorus}

The phosphorus $(\mathrm{P})$ content in fuels is a potent poison for the advanced emission control equipment on new diesel vehicles. The current specification limit is $10 \mathrm{ppm}$ or less for B100. Using the current method, D4951, the detection limit for phosphorus is $<5 \mathrm{ppm}$ and has been illustrated as $5 \mathrm{ppm}$ in Figure 4. In this study, only one sample (\#45) failed to meet the phosphorus specification. This sample was also off specification for five other properties; thus, it represents one of the lowest quality samples obtained in this study.

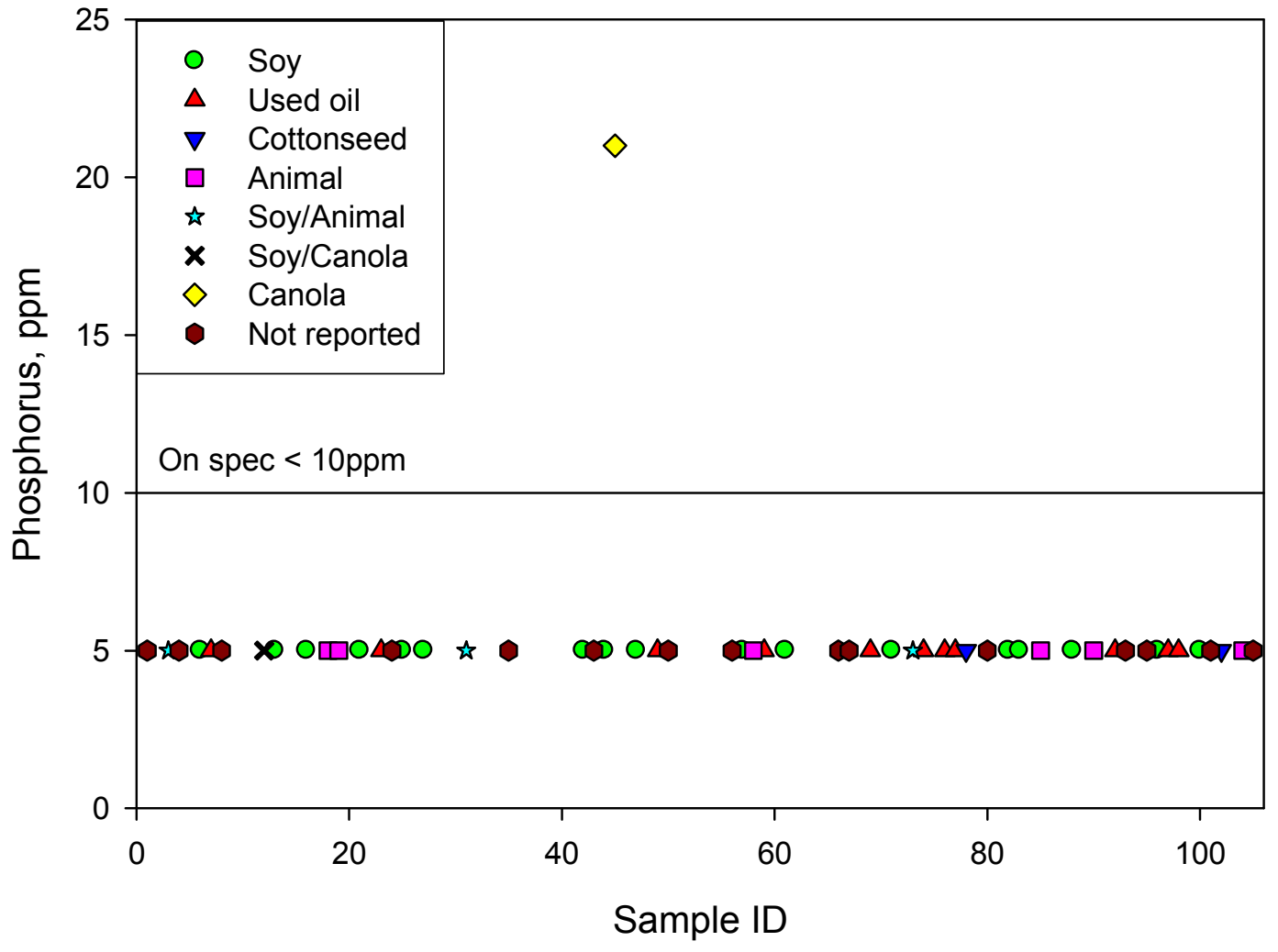

Figure 4. Phosphorus content of B100 samples 


\section{Free and Total Glycerin}

High levels of glyercin and glyceride species can lead to deposits and cold weather operability problems in diesel engines. All the samples received in this study were B100, in comparison to those of the 2006 survey, in which six of 39 samples were B99.9 and could not be tested for free and total glycerin.

Three samples (5.5\%) failed to meet the free glycerin specification of 0.020 mass $\%$ (Figure 5). As we observed in previous surveys, the samples either easily pass or grossly fail the free glycerin specification. Very rarely does a sample marginally pass or fail this test.

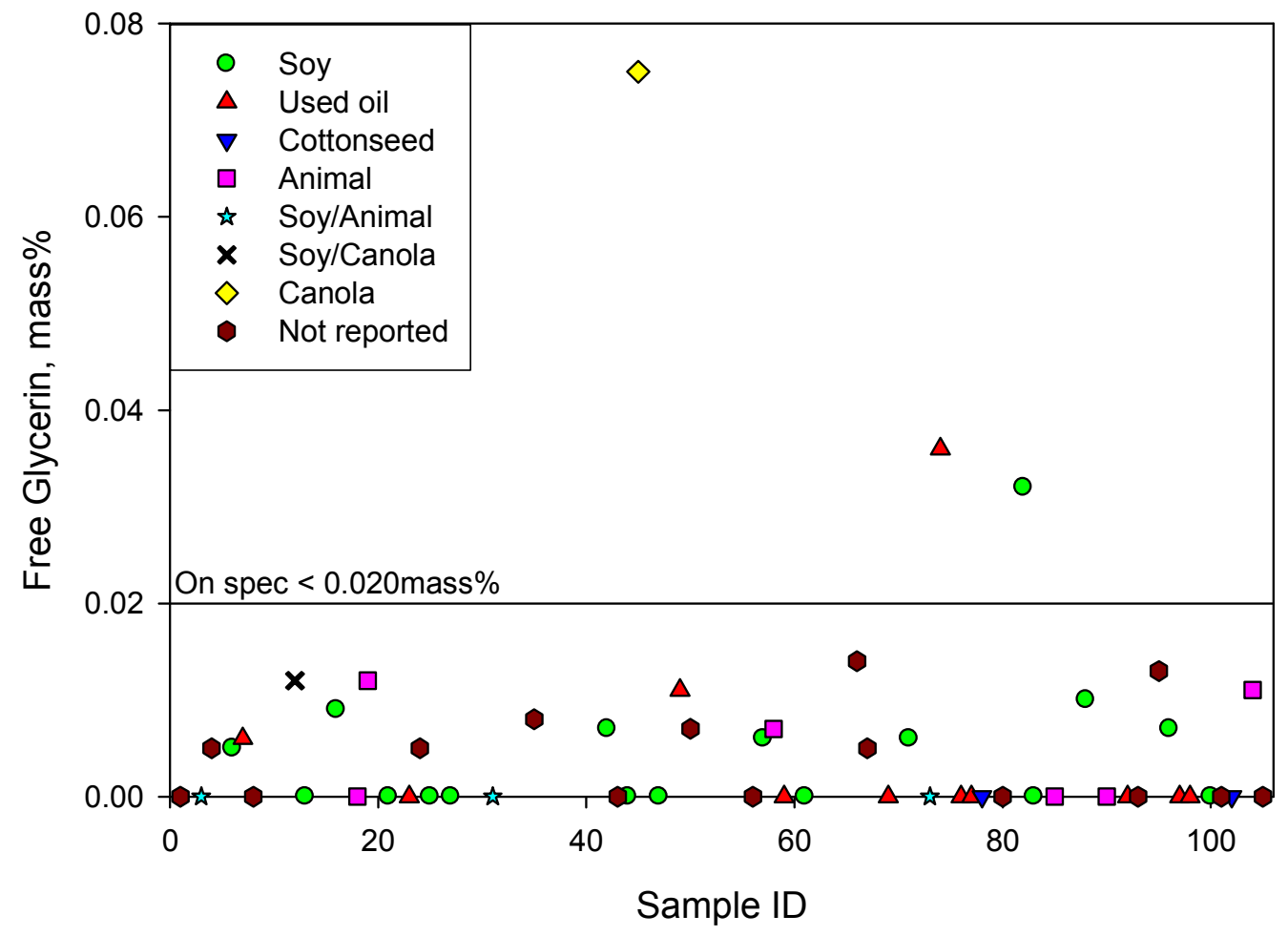

Figure 5. Free glycerin content of B100 samples 
The failure rate for total glycerin, as illustrated in Figure 6, was somewhat higher than that for free glycerin; five samples were off specification ( $8.9 \%)$. Two samples were marginally high for total glycerin (\#74 and \#80), and the other three samples represented gross failures.

A wide range of values was observed for total glycerin. Several samples were only marginally on specification ( 0.20 to 0.240 mass $\%$ ), and two were marginally off specification (0.240 to 0.30 mass\%). Only two samples were off specification for free and total glycerin.

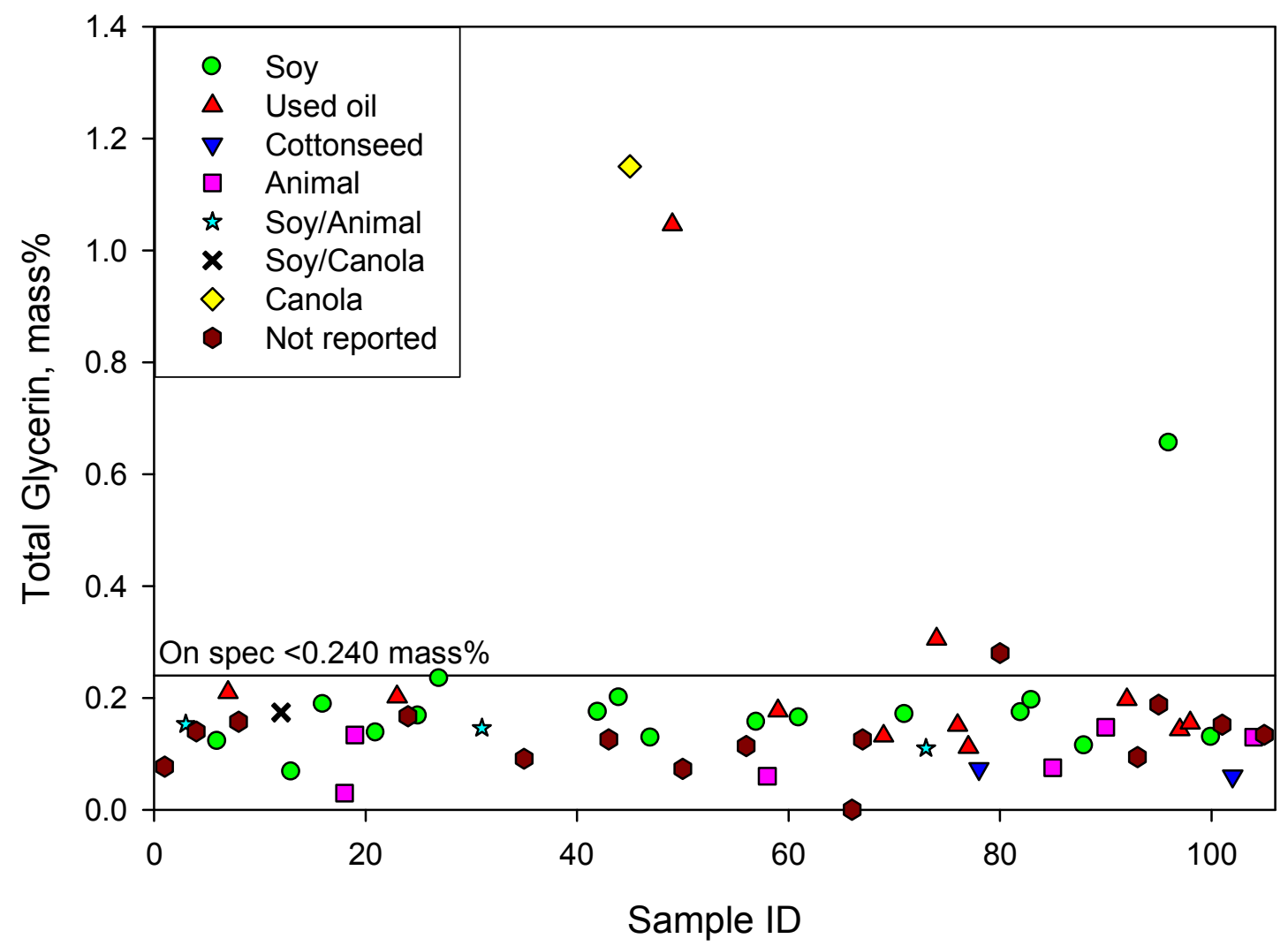

Figure 6. Total glycerin for B100 samples 
An interesting way to look at glycerin species is by plotting the mono-, di-, and triglycerides, as shown in Figure 7. Typically, samples can pass the total glycerin specification with $1 \%$ or less glycerides.

As shown in the five samples that failed for total glycerin, high mono-, di-, or triglycerides can cause a sample to fail the specification. Sample \#96 is unusual because it has a diglyceride level higher than either the mono- or triglycerides. The transesterification reaction proceeds sequentially, so that we expect the concentration of monoglycerides $>$ diglycerides $>$ triglycerides. It is unclear why the diglyceride content of this sample is so high.

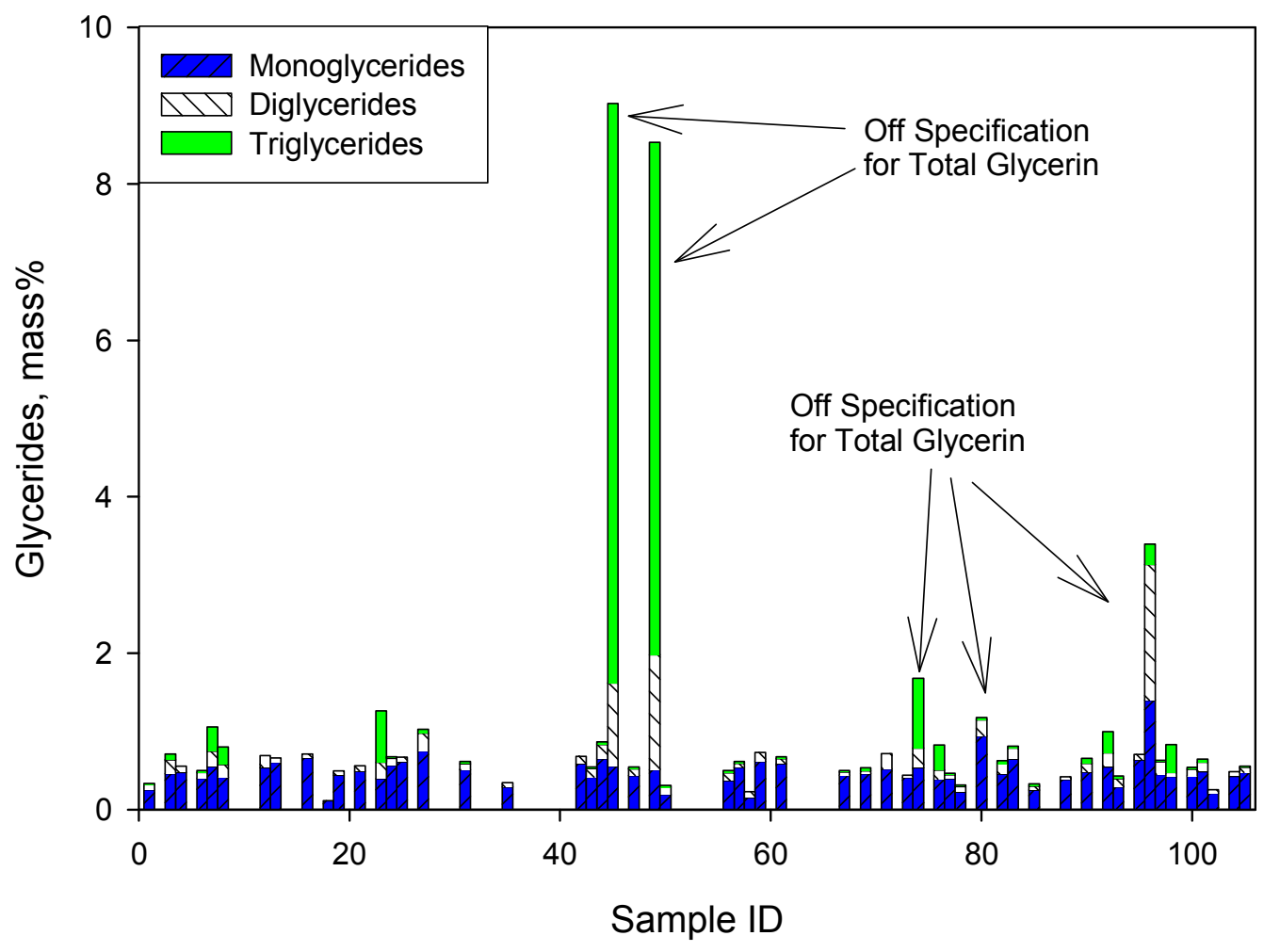

Figure 7. Mono-, di- and triglyceride content of biodiesel samples 


\section{Acid Value}

The acid value of biodiesel is one of the first parameters to increase as the fuel ages. Out of the 56 samples collected, four samples (7\%) failed to meet the specification of 0.50 milligrams potassium hydroxide per gram of sample (mg KOH/g) (Figure 8).

Two samples had extremely high acid values, and each of those samples also failed tests for multiple properties. Sample \#8 failed acid value only and was on specification for all other properties. The sample was collected within 2 weeks of manufacture and analyzed shortly thereafter, so the fuel was unlikely to be very old. Sample \#104 was also collected and analyzed within a few weeks of manufacture, but this sample also failed the calcium + magnesium $(\mathrm{Ca}+\mathrm{Mg})$ specification.

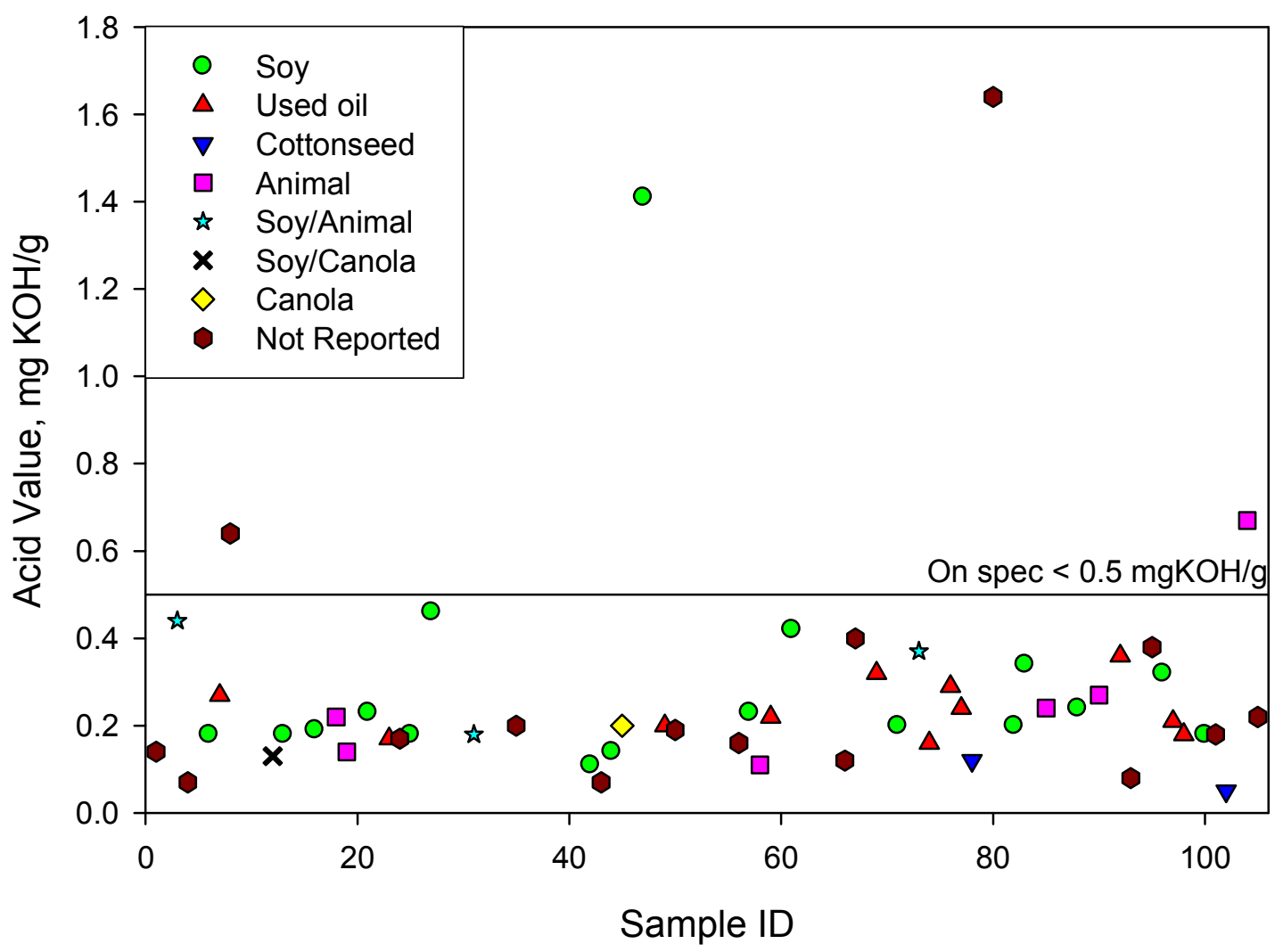

Figure 8. Acid value of B100 samples 


\section{Metals}

High levels of Group I and II metals - such as sodium (Na), potassium (K), calcium $(\mathrm{Ca})$, and magnesium $(\mathrm{Mg})$ - can cause deposits to form, catalyze undesired side reactions, and poison emission control equipment. The Group I and II metals are limited as the combination of metals in each category, $\mathrm{Na}+\mathrm{K}$ and $\mathrm{Ca}+\mathrm{Mg}$. For each combination, the limit is 5 ppm.

Three samples had $\mathrm{Na}+\mathrm{K}$ higher than the 5-ppm limit (\#4, \#44, and \#74). Samples \#4 and $\# 44$ failed the $\mathrm{Na}+\mathrm{K}$ specification as well as the oxidation stability specification. Sample \#74 was off specification for multiple properties. Sample \#45 could not be tested by this method because of its excess methanol content, which interferes with the instrument and was off specification for multiple properties. The data are shown in Figure 9. Note that, for $\mathrm{Na}$ and $\mathrm{K}$, the lower limit of detection was $1 \mathrm{ppm}$ for each metal, so much of the data was reported as $<1 \mathrm{ppm}$. Each result was assigned a value of $1 \mathrm{ppm}$ for purposes of illustration in Figure 9, resulting in a combined value of $2 \mathrm{ppm}$. The results for $\mathrm{Na}+\mathrm{K}$ are overwhelmingly below the specification, with over $90 \%$ below the detection limit.

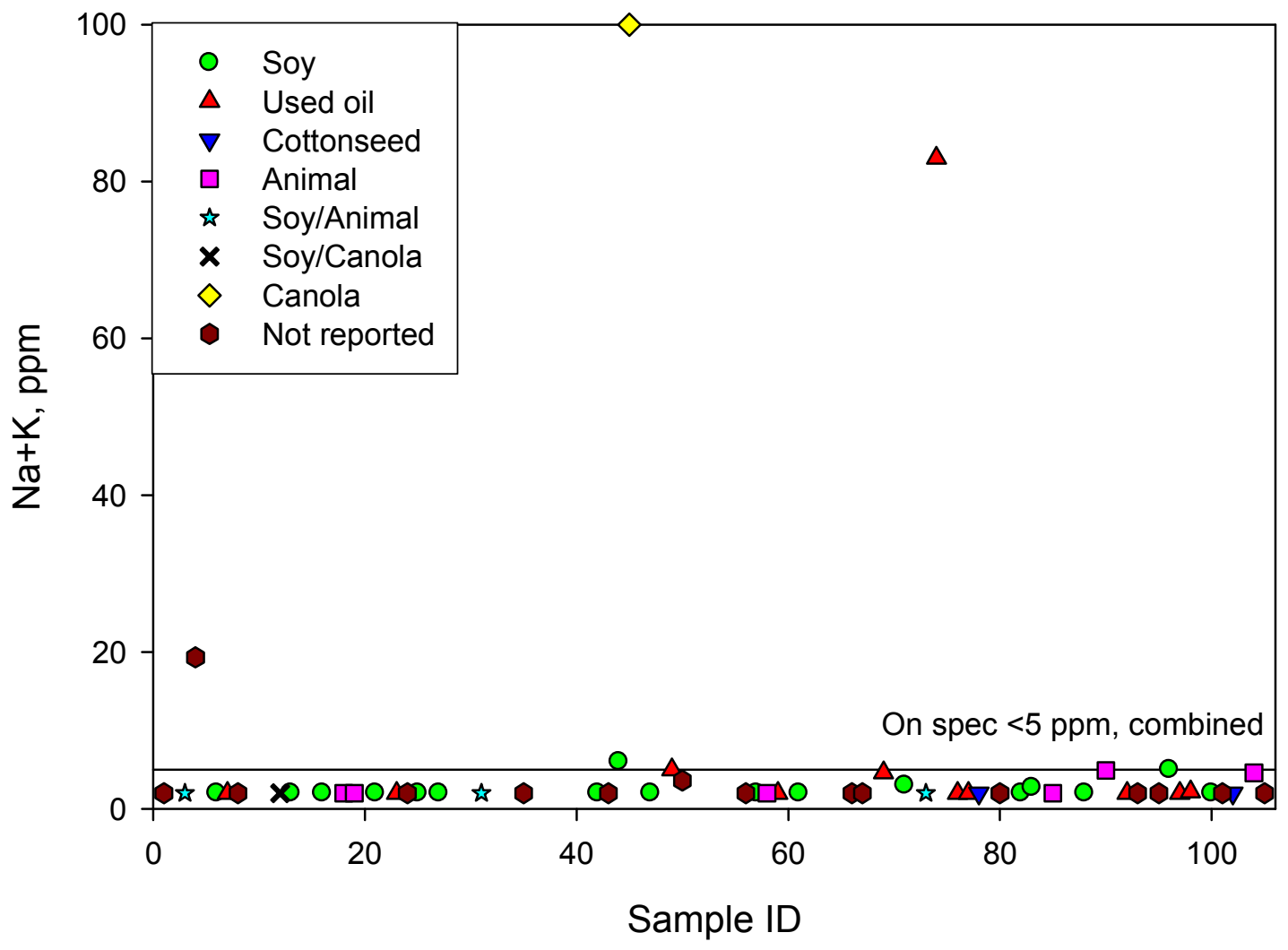

Figure 9. Na+K content of B100 samples 
Figure 10 shows the $\mathrm{Ca}+\mathrm{Mg}$ content for the samples collected in this survey. Note that the $\mathrm{y}$-axis is plotted as the $\log$ of the $\mathrm{Ca}+\mathrm{Mg}$ content to better illustrate the range of the results. The detection limits for these metals is much lower than those for $\mathrm{Na}+\mathrm{K}$, and values were reported down to $100 \mathrm{ppb}$ for each metal. For illustration purposes, samples with levels below the detection limit were assigned values at the sum of the detection limit of $2 \mathrm{ppb}$, combined, for each metal.

As with the $\mathrm{Na}+\mathrm{K}$, sample \#45 was not analyzed for this parameter because of interference with the instrument. Only three samples failed to meet the 5-ppm limit \#78, $\# 90$, and \#104. Samples \#78 and \#90 only failed to meet the $\mathrm{Ca}+\mathrm{Mg}$ limit, while sample \#104 was also off specification for acid value. More than $90 \%$ of the samples were below the specification limit of $5 \mathrm{ppm}$.

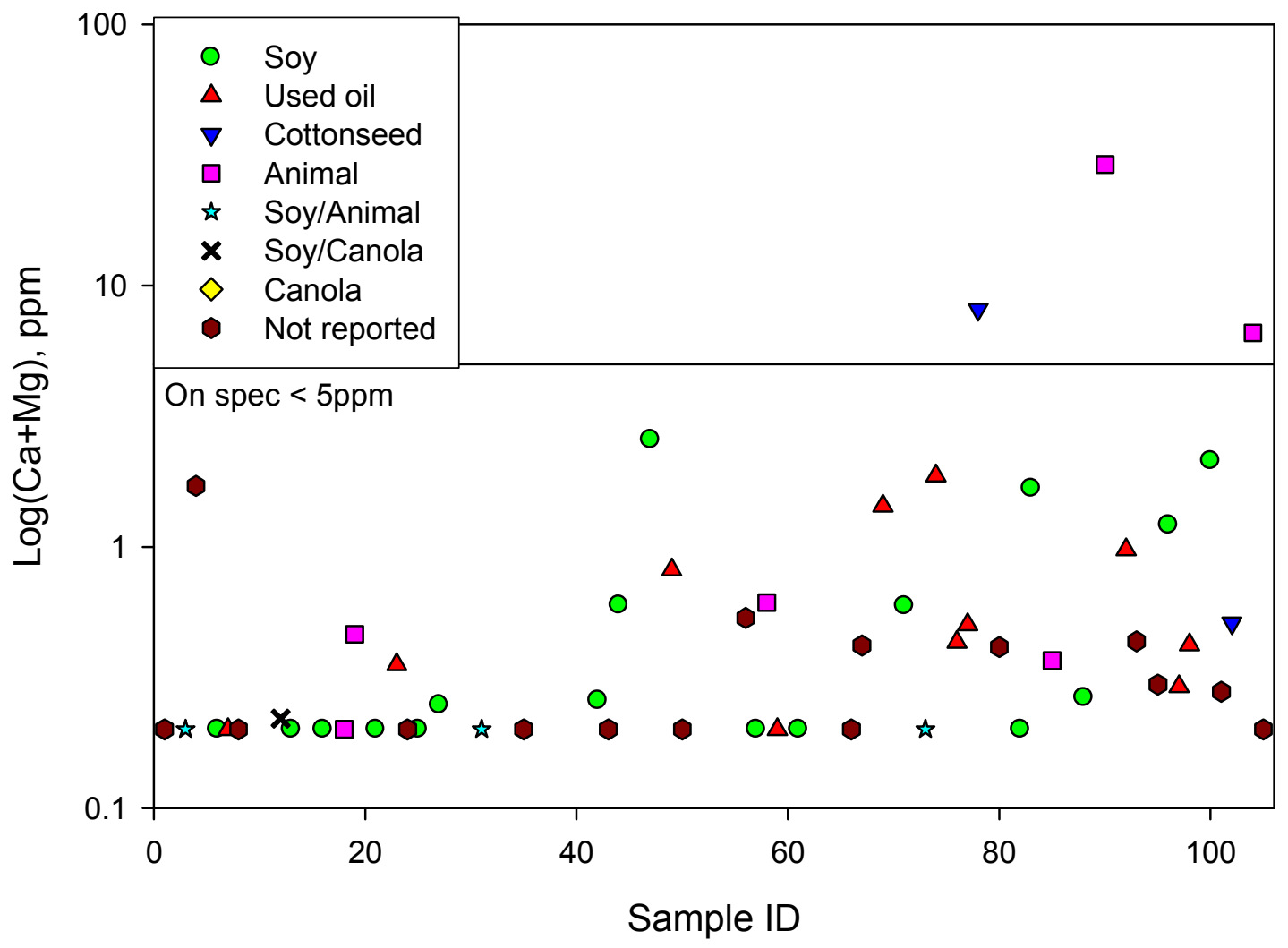

Figure 10. Ca+Mg content of B100 samples 


\section{Flash Point and Alcohol Content}

Methanol content in biodiesel is limited by requiring the flash point to be above $130^{\circ} \mathrm{C}$ or above $93^{\circ} \mathrm{C}$ with methanol as measured by gas chromatography of less than $0.20 \mathrm{wt} \%$. Biodiesel that meets these limitations is classified as nonhazardous under the National Fire Protection Association Code. The limitation on flash point and alcohol content was added to D6751 in 2007, revision D6751-07a.

In the previous study, the failure to meet the flash point was significant; $33 \%$ of samples failed to meet the specification. The current samples are much improved for flash point; there was only a 5.5\% failure rate (three samples; see Figure 11). Of these, two samples had flash points below $93^{\circ} \mathrm{C}$, indicating that excess methanol was present. As stated earlier, sample \#44, with a flash point of $27^{\circ} \mathrm{C}$, was off specification for multiple properties. Sample \#59, with a flash point of $67^{\circ} \mathrm{C}$, was also off specification for oxidation stability.

Several samples had flash points between $93^{\circ} \mathrm{C}$ and $130^{\circ} \mathrm{C}$. These samples were analyzed for methanol content by EN14110. Of the eight samples analyzed, only one had excess methanol content and thus failed the alcohol content specification.

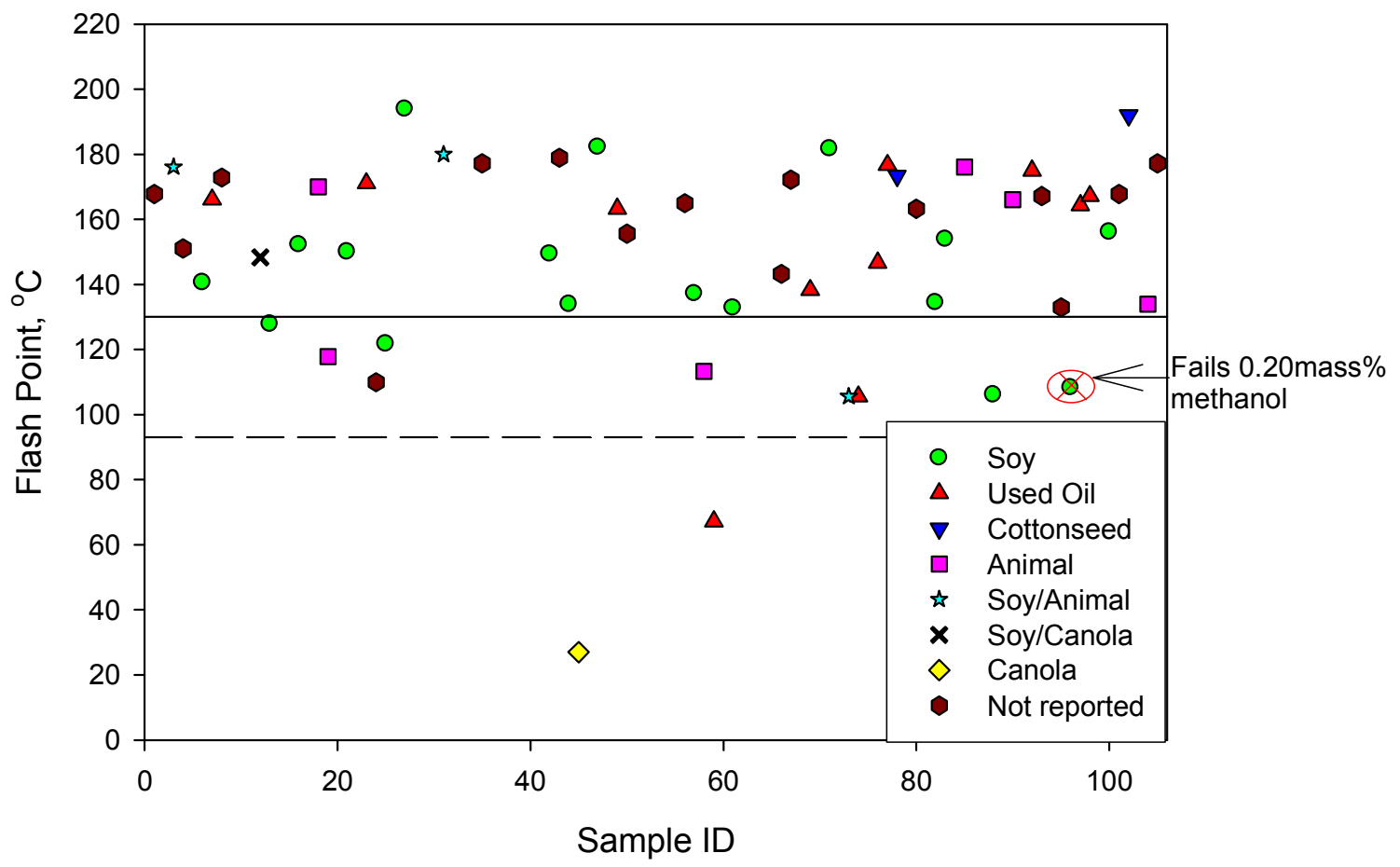

Figure 11. Flash point results for B100 quality survey 


\section{Oxidation Stability}

The specification for oxidation stability was added to D6751 in January 2007. Samples were tested for oxidation stability within 1 week of receipt by the contractor to ensure as accurate a result as possible. Seventeen out of 56 samples, or $30 \%$, did not meet the specification of a 3-h minimum for oxidation stability (Figure 12). Nine out of these 17 samples were on specification for all other properties; the eight remaining samples failed for multiple properties.

Another way to look at oxidation stability is to use a histogram (Figure 13). The samples in this program were essentially bimodal. The average oxidation stability is $4.1 \mathrm{~h}$, the median is $4.4 \mathrm{~h}$, and the mode is only $3.2 \mathrm{~h}$.

Biodiesel from used oils failed to meet the oxidation stability specification more often than other feedstocks represented in this study. Two possible reasons have been proposed for these failures.

First, used oils have been thermally stressed and therefore may have high levels of peroxides. These peroxides may carry over into the biodiesel. Antioxidants prevent peroxides from forming, but cannot prevent those oxidation products from forming if peroxides are already present. Poor oxidation stability may result for oxidized oils even if synthetic antioxidants are added.

Second, the original source for the used oils may have been soybean oil, which has naturally high linolenic and linoleic content. Soybean oil also has fairly high levels of natural antioxidants. However, thermal stressing combined with high levels of reactive polyunsaturated fatty acids may have led to the consumption of these natural antioxidants, resulting in poor stability for the ultimate biodiesel product. 


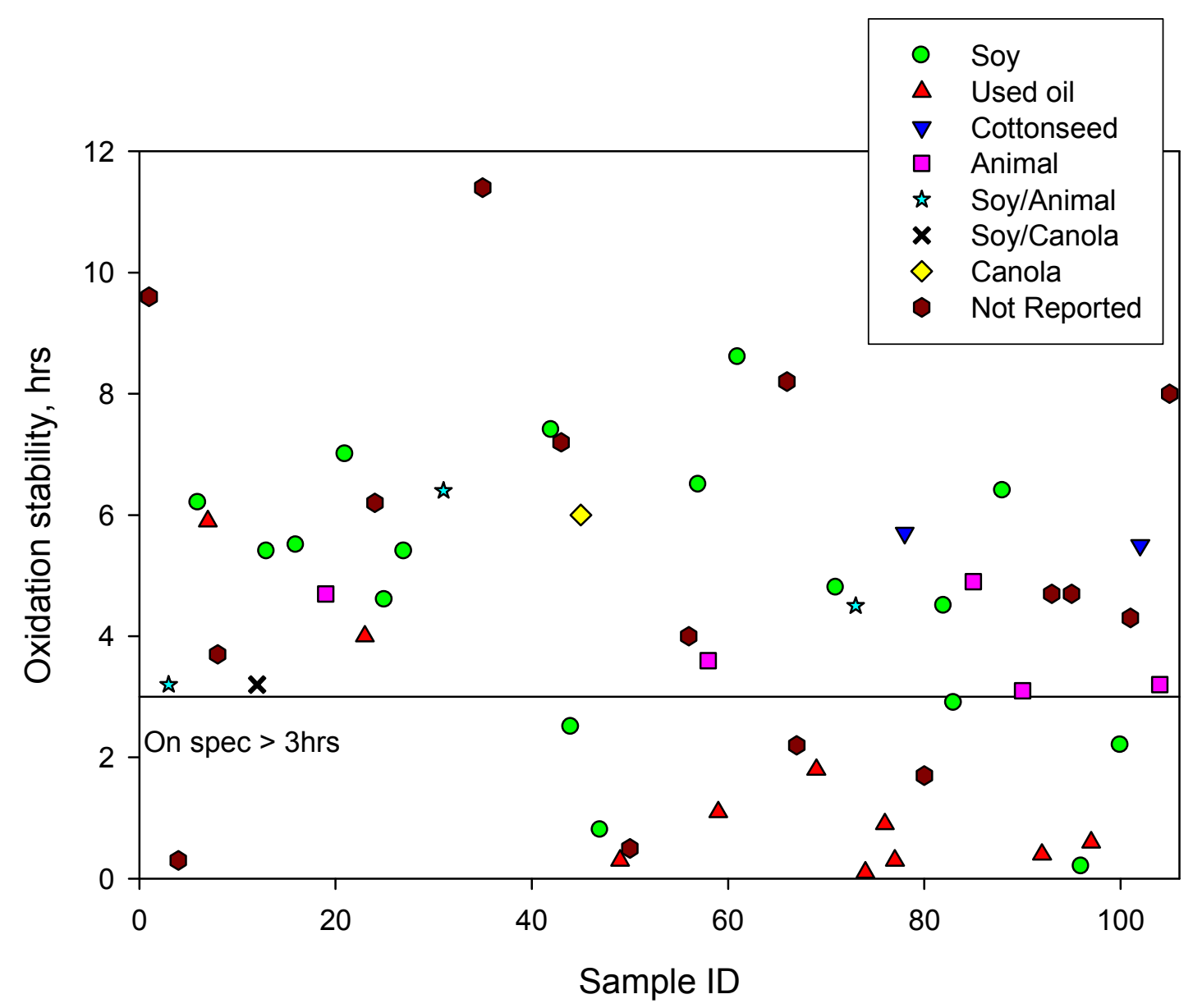

Figure 12. Oxidation stability results for B100 samples 


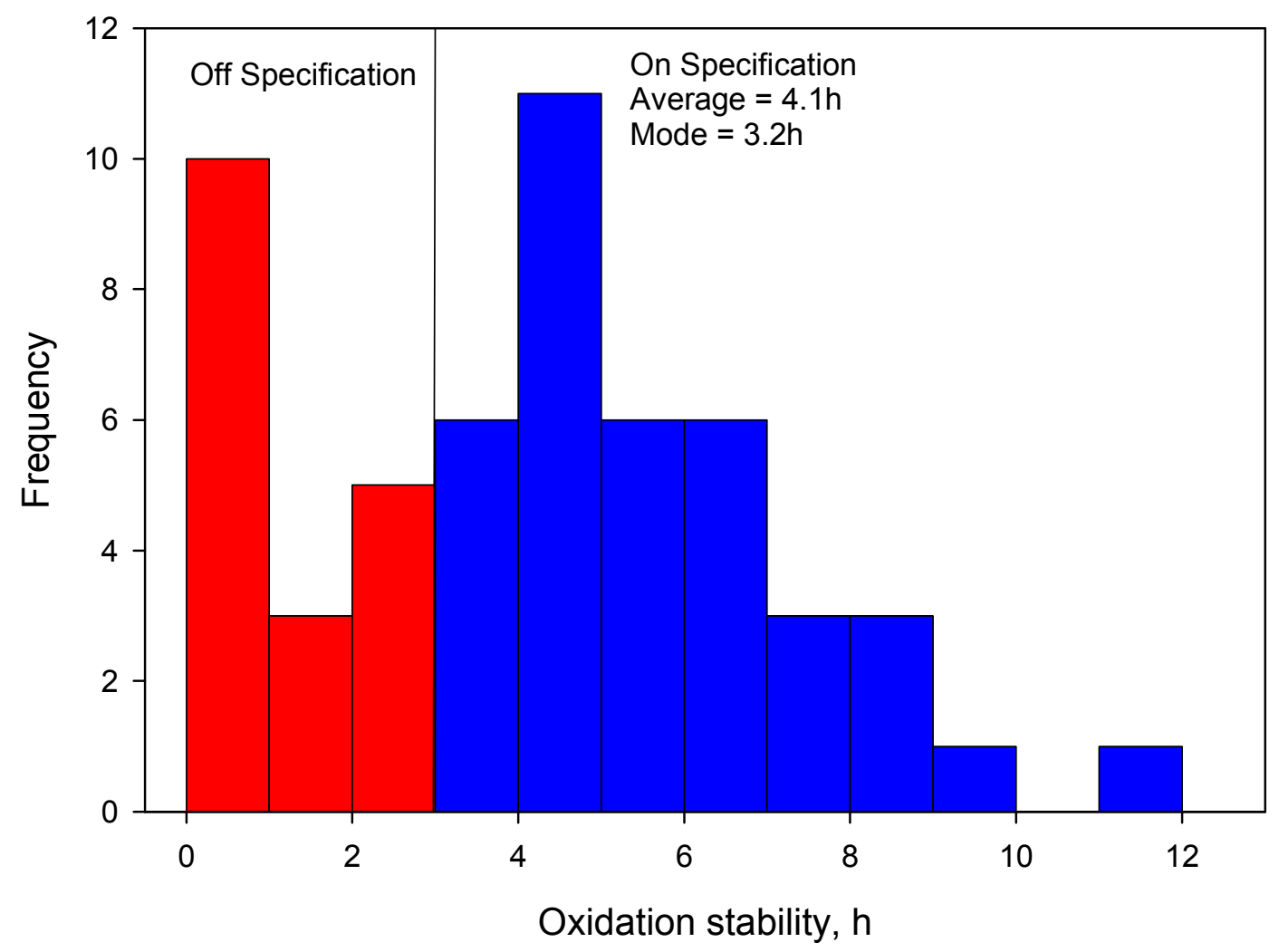

Figure 13. Oxidation stability histogram for biodiesel samples

\section{Discussion of Results on a Production Volume Basis}

Another way to examine the quality of the B100 samples collected in this survey is to weight the failure rate by production volume. As discussed above, producers were grouped into small, medium, and large categories. The large producers were responsible for $89 \%$ of the 287 million gallons represented in the survey, or 247.42 million gallons. The medium producers were responsible for $10 \%$ of the market, and the small producers were responsible for the remaining one percent. Producers within each category were assumed to produce an equal share of the category. Thus, each of the 15 producers that was classified as large was assumed to be responsible for 16.5 million gallons.

The samples collected in this survey covered approximately $70 \%$ of the total biodiesel market in 2007 and can be assumed to be representative of the market as a whole. Producers that did not respond to the survey request were almost exclusively small producers. The producers that did not participate in the study were assumed to have pass/fail rates similar to their respective size categories.

As stated earlier, off-specification samples most often came from small and medium producers. Based on the assumptions noted above, less than 2 million gallons of the 287 
million gallons surveyed in 2007 failed the specifications for flash point and alcohol content, $\mathrm{P}, \mathrm{Ca}+\mathrm{Mg}, \mathrm{Na}+\mathrm{K}$, and free and total glycerin.

The highest failure rate was observed for oxidation stability, at $30 \%$, which equates to roughly 8.5 million gallons of biodiesel of the 287 million gallons sampled. The one sample that failed the water and sediment specification was from a large producer. Assuming that the high water and sediment rate for this sample was not the result of contamination - which is unlikely because of the high quality of the other propertiesthis failure would represent approximately 24 million gallons of biodiesel production.

Based on these production volume estimates, $90 \%$ of the biodiesel produced in 2007 met the D6751 requirements for the properties measured (except sulfur).

\section{Summary and Conclusions}

Biodiesel production continues to grow rapidly. To sustain this growth and foster new growth, it is critical that fuels have reliable quality and be on specification. In order to evaluate the quality of U.S. biodiesel, samples were collected from domestic producers from April to November 2007. During the study, 107 producers were in the market. Fiftysix of them participated in the study. Most often, the remaining producers were unresponsive to multiple attempts to collect a sample.

Biodiesel production capacity can be categorized into three sizes - small, medium, and large. Twenty-five small producers, producing less than 100,000 gallons per year each, responded to this survey. Sixteen medium producers (those producing between 100,000 and 1 million gallons per year) responded, and fifteen large producers (those producing greater than 1 million gallons per year) participated. Fourteen of the large producers and three medium ones were also BQ-9000 companies.

Biodiesel samples were tested for properties critical to engine operability and the durability of the emission control system - flash point, free and total glycerin, cloud point, acid value, and water and sediment — as well as for phosphorus and metals. Based on production volume estimates from the National Biodiesel Board, we estimate that $90 \%$ of the biodiesel production capacity in the United States met the specifications. Almost without fail, large producers and those participating in the BQ-9000 program produced on-specification biodiesel. Small and medium producers who were not BQ-9000 companies had more difficulty in meeting the specifications, although their overall production capacity was a small fraction of the capacity of the large producers.

Small and medium producers most often failed to meet the oxidation stability specification, although failing samples were approximately 8.5 million gallons out of 287 million gallons in the survey. Failures for other properties tested were less than 2 million gallons. The overall quality of biodiesel has improved over that found in previous studies, but significant lapses in quality still exist. For the biodiesel market as a whole, these success rates can be considered representative; thus, $90 \%$ of the biodiesel produced in 2007 was likely on specification. 


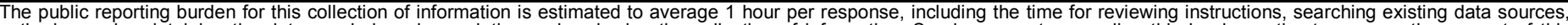

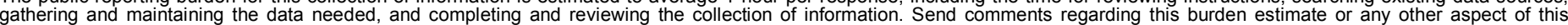

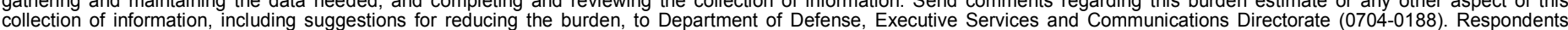

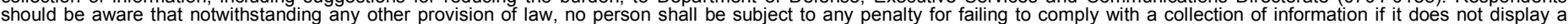

should be aware that notwithstanding

PLEASE DO NOT RETURN YOUR FORM TO THE ABOVE ORGANIZATION.

\begin{tabular}{l|l|l|l} 
1. REPORT DATE $(D D-M M-Y Y Y Y)$ & 2. REPORT TYPE & 3. DATES COVERED (FrOm - TO)
\end{tabular}

March 2008

Technical Report

4. TITLE AND SUBTITLE
Results of the 2007 B100 Quality Survey

5a. CONTRACT NUMBER

DE-AC36-99-G010337

5b. GRANT NUMBER

5c. PROGRAM ELEMENT NUMBER

6. AUTHOR(S)

T. L. Alleman and R. L. McCormick

5d. PROJECT NUMBER

NREL/TP-540-42787

5e. TASK NUMBER

FC08.9400

5f. WORK UNIT NUMBER
7. PERFORMING ORGANIZATION NAME(S) AND ADDRESS(ES)

National Renewable Energy Laboratory

1617 Cole Blvd.

Golden, CO 80401-3393
8. PERFORMING ORGANIZATION REPORT NUMBER

NREL/TP-540-42787

9. SPONSORING/MONITORING AGENCY NAME(S) AND ADDRESS(ES)

10. SPONSOR/MONITOR'S ACRONYM(S) NREL

11. SPONSORING/MONITORING AGENCY REPORT NUMBER

12. DISTRIBUTION AVAILABILITY STATEMENT

National Technical Information Service

U.S. Department of Commerce

5285 Port Royal Road

Springfield, VA 22161

13. SUPPLEMENTARY NOTES

14. ABSTRACT (Maximum 200 Words)

The National Renewable Energy Laboratory conducted a biodiesel (B100) quality survey in 2007 after collecting samples from 56 of the 107 U.S. producers that were contacted. Researchers compared the samples against BQ9000 critical properties (except sulfur) and metals, using ASTM test methods, for oxidation stability, flash point (or methanol content), cloud point, water and sediment, acid value, and free and total glycerin. Samples were also analyzed for phosphorus, calcium, potassium, magnesium, and sodium, which can greatly harm advanced emissions control equipment. Although failure rates were high on the basis of percentage of samples collected, volumeweighting indicated that only $10 \%$ of U.S. biodiesel failed to meet requirements. The BQ-9000 companies, regardless of production volume, had extremely low failure rates in comparison to the overall population of biodiesel producers.

15. SUBJECT TERMS

Biodiesel; B100; alternative fuels; biofuels; fuel standards; B100 quality survey

\begin{tabular}{|c|c|c|}
\hline 16. SECURIT & CLASSIFICATI & N OF: \\
\hline $\begin{array}{l}\text { a. REPORT } \\
\text { Unclassified }\end{array}$ & $\begin{array}{l}\text { b. ABSTRACT } \\
\text { Unclassified }\end{array}$ & $\begin{array}{l}\text { c. THIS PAGE } \\
\text { Unclassified }\end{array}$ \\
\hline
\end{tabular}

\begin{tabular}{l|l|}
$\begin{array}{l}\text { 17. LIMITATION } \\
\text { OF ABSTRACT }\end{array}$ & 18. $\begin{array}{l}\text { NUMBER } \\
\text { OF PAGES }\end{array}$ \\
UL &
\end{tabular}

19a. NAME OF RESPONSIBLE PERSON

19b. TELEPHONE NUMBER (Include area code) 